$$
\text { DOE/PC/95150-T1 }
$$

Final Technical Progress Report

Covering the Period Oct 1, 1995 to June 30, 1996

\title{
AN ADVANCED CONTROL SYSTEM FOR FINE COAL FLOTATION
}

Prime Contractor

Control International, Inc. c/o GS Industries

1901 Roxborough Rd, Ste. 200

Charlotte, NC 28211

Contract Number

DE-AC22-95PC95150

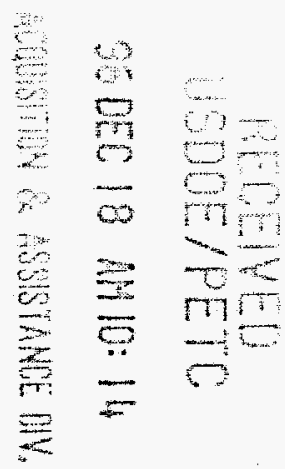

HH OISTRIBUTION OF THIS DOCUMENT IS UNLIMITESD

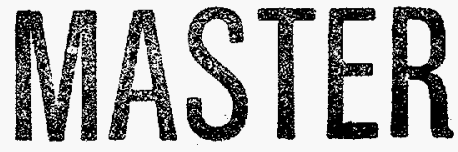

November 26, 1996

"US/DOE patent clearance is not required prior to the publication of this document." 


\section{DISCLAIMER}

This report was prepared as an account of work sponsored by an agency of the United States Government. Neither the United States Government nor any agency thereof, nor any of their employees, make any warranty, express or implied, or assumes any legal liability or responsibility for the accuracy, completeness, or usefulness of any information, apparatus, product, or process disclosed, or represents that its use would not infringe privately owned rights. Reference herein to any specific commercial product, process, or service by trade name, trademark, manufacturer, or otherwise does not necessarily constitute or imply its endorsement, recommendation, or favoring by the United States Government or any agency thereof. The views and opinions of authors expressed herein do not necessarily state or reflect those of the United States Government or any agency thereof. 


\section{DISCLAMMER}

Portions of this document may be illegible in electronic image products. Images are produced from the best available original document. 


\begin{abstract}
This report includes the quarterly reports for the periods: Oct 1- Dec 31, 1995; Jan 1 - Mar 31, 1996 and Apr 1 - Jun 30, 1996.

A model-based flotation control scheme is being implemented to achieve optimal performance in the handling and treatment of fine coal. The control scheme monitors flotation performance through on-line analysis of ash content. Then, based on the economic and metallurgical performance of the circuit, variables such as reagent dosage, air addition rate, pulp density and pulp level are adjusted using model-based control algorithms to compensate for feed variations and other process disturbances. Recent developments in video-based sensor technology are being applied for on-line determination of slurry ash content.

During the third quarter of this project, work continued on the testing and calibration of the video-based ash analyzer, and a plant sampling campaign was conducted to provide data for the development of a mathematical process model and the model-based control algorithms.
\end{abstract}




\section{INTRODUCTION}

Over the past thirty years, process control has spread from the chemical industry into the fields of mineral and coal processing. Process computers, combined with improved instrumentation for monitoring process parameters and performance, have demonstrated improved process control in modern flotation plants. However, the classical methods used in most control strategies have some severe limitations in the control of flotation plants. The nonlinear nature of flotation processes can cause single-input, single-output control loops to battle each other in attempts to achieve single objectives. Other problems experienced in classical control schemes are noisy signals from measuring sensors and the inability to measure certain process variables. Factors related to ore type or process water chemistry, such as liberation characteristics, froth stability and floatability, cannot be measured by conventional sensors.

The purpose of this project is to demonstrate an advanced control system for fine coal flotation. The demonstration is being carried out at the Maple Meadow Coal Preparation Plant owned and operated by Cyprus Amax Coal Company. The objectives of this work are: 1) to identify through sampling, analysis and simulation those variables which can be manipulated in the plant to maintain grades, recoveries and throughput rates at levels set by management; 2) to develop and implement a model-based computer control strategy that continuously adjusts those variables to maximize revenue subject to various metallurgical, economic and environmental constraints; and 3) to employ a video-based optical analyzer for on-line analysis of ash content in fine coal slurries. The following is a summary of work completed during the first three quarters of this project. 


\section{PROJECT TASKS}

\section{Task 1- Project Planning}

Subtask 1.1 - Work Plan. A revised work plan is still to be submitted.

Subtask 1.2 - Project Management. Following reorganization and changes at Control International, the overall management of this project is currently being handled through a consulting agreement with GS Industries by J. A. Herbst and Associates in Salt Lake City. As a result of this reorganization, a number of reports have been delayed and several tasks are $4-5$ months behind schedule. Negotiations are currently underway with DOE as to the future management structure of this project.

\section{Task 2 - Plant Sampling and Data Analysis}

Subtask 2.1 - Testing. A detailed sampling campaign around the first flotation bank (see Figure 1) at the Maple Mining coal preparation plant in Fairdale, WV was carried out during the week of April 15. Personnel from Control International, VPI\&SU and Maple Meadow participated in this effort. This flotation bank is the one that will be equipped with instrumentation and computer control strategy. For the model building and simulation in Task 3 the following tests and sampling were performed during the week of April 15:

1. A $2^{3}$ factorial design test to determine the effects of feedrate, reagent dosage and pulp level on the performance of the flotation bank and to estimate parameters of a phenomenological model of flotation.

2. A residence distribution test with a lithium chloride tracer.

3. A series of feed samples taken to determine the variability of the coal floatability characteristics.

In the $2^{3}$ factorial design the manipulated variables take two levels, -1 and +1 , which represent high and low values. The eight possible combinations and two center points (at 0 ) are shown in Table 1 and the schematic in Figure 2. To begin each test the manipulated variables were set to the values called for in Table 1 and the flotation circuit allowed to run for one hour at those values before taking samples so that the flotation bank could reach steady state. As shown in Figure 1, samples of feed, concentrate and tails were taken with an automated sample system that used pipes to transport samples from sample ports near the flotation bank to a collection station on the bottom floor of the plant. Sample collection was very convenient with this 
system. The samples were analyzed for size distribution, specific gravity distribution, percent solids, sulfur and ash. Appendix I shows the analysis of the samples.

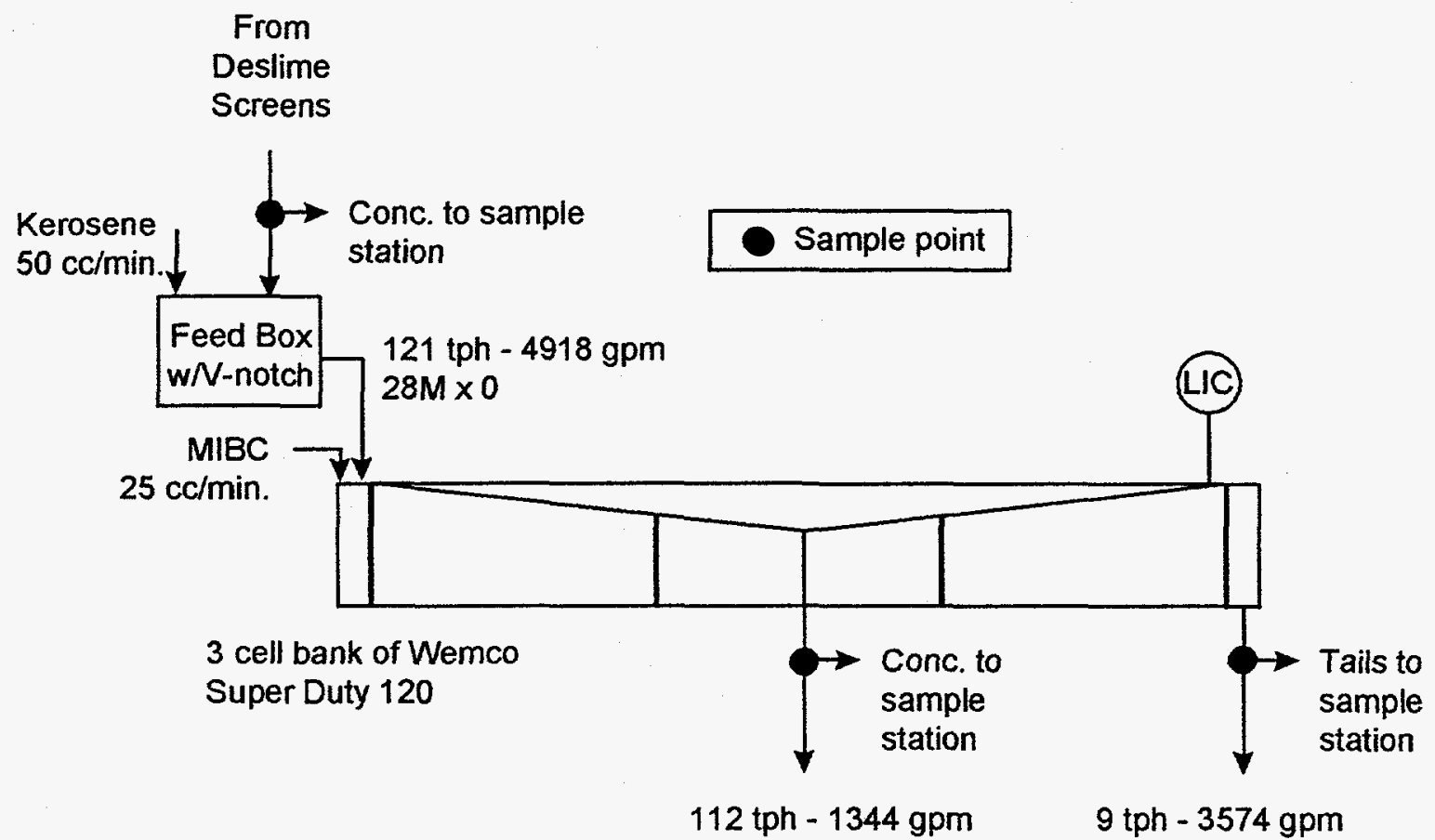

Figure 1. The flotation bank and sampling points.

Table 1. Factorial Design Tests Summary

\begin{tabular}{cccc}
\hline Test & Feedrate & Reagent & Level \\
\hline 1 & -1 & -1 & +1 \\
2 & +1 & +1 & +1 \\
3 & +1 & -1 & -1 \\
4 & -1 & +1 & -1 \\
5 & +1 & -1 & +1 \\
6 & -1 & +1 & +1 \\
7 & -1 & -1 & -1 \\
8 & +1 & +1 & -1 \\
9 & 0 & 0 & 0 \\
10 & 0 & 0 & 0 \\
\hline
\end{tabular}

Pulp level was controlled by a Foxboro controller and a bubble tube at the end of the flotation bank. The pulp controller indicated level on a scale of 0 to 100 so to obtain pulp distance from the lip of the cell a simple device was employed. Pulp level in the first cell was 
measured with a string tied to an ordinary plastic bottle partially filled with slurry. When the bottle is dipped into the pulp it sinks until the level of slurry in the bottle is the same as the slurry in the flotation cell. The bottle was suspended on the string from a beam above the cell and the distance from that point to the top of the slurry in the bottle was measured. Only the pulp level was measured in the first cell because the froth paddles on the last two cells made it difficult to measure the pulp level. The height of pulp in the feed box V-notch was measured.

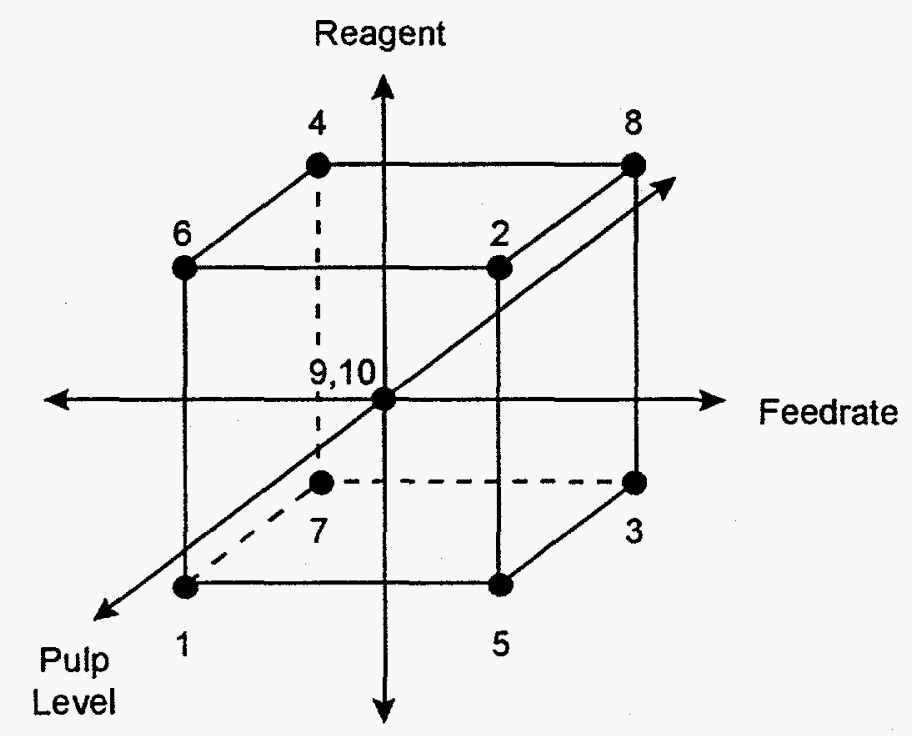

Figure 2. Steady state $2^{3}$ factorial design experiments.

One residence time distribution test was performed. One kilogram of lithium chloride was dissolved in 4 liters of water and injected at time 0 into the flotation bank feed (as a "pulse"). Starting at time 0 , a series of samples were taken from a box at the end of the flotation bank with a $500 \mathrm{ml}$ sample bottle. The supernatent liquid from the sample bottle was analyzed for $\mathrm{LiCl}$ concentration. The analysis of the RTD samples are reported in Appendix II.

To characterize floatability variations a series of batch flotation tests were performed with flotation bank feed samples collected at progressively longer intervals between samples. Initially samples are taken frequently to catch rapid variations and then at geometrically longer sample times to catch less frequent changes. The geometric series is shown in Appendix III. The most precise way to determine the mean time between floatability changes is with equally spaced samples taken close together for up to 24 hours. This leads to an unacceptable large 
number of batch flotation tests to be performed. The geometric progression of intervals greatly reduces the number of samples but it can catch short term as well as long term disturbances. However it is less precise than the equally spaced samples. The sequence of sample times is shown in Appendix III.

When a sample was taken, it was immediately brought to the batch flotation cell on the plant floor so that the chemistry of the batch flotation matched that of the actual plant as closely as possible. The sample was floated in the batch cell for 2 minutes and the froth collected during that time. The froth and tails were filtered and analyzed solely for ash content. Only a first order rate constant can be estimated in this manner but such a rate constant is influenced by numerous mechanisms that are sensitive to the properties of the coal particle surface. The variability of coal floatability can be mimiced with a dynamic flotation simulator by random changes in the rate parameters that have the same magnitude and time-between-changes as that estimated for the plant feed coal.

\section{Analysis for Model Building}

Table 2 shows the actual plant feedrate (tph), measured pulp levels, ash percent and yield for each test. The yield was calculated from the ash percent. Figure 3 shows a bar graph of the ash content of feed, concentrate and tails. The feed ash percent is fairly stable except for tests 2 and 9 in which the feed ash \% is a few percent higher than the others. The actual plant tonnage generally met the target except for tests 1 and 9 when the operator had to change the plant feedrate to correct conditions elsewhere in the plant. The measured pulp level was close to the targets although the imprecision of the manual pulp level measuring device is not known. Concentrate grade does not change much although tails ash \% and yield do show the magnitude of responses expected from factorial design tests.

The ash content can be computed from the ash content of individual size and density fractions. Table 3 shows ash content computed in this manner and the yield. For the comparison the directly analyzed ash content from Table 2 is shown alongside the computed ash content. As seen in Figures 4, 5 and 6, the computed ash content is not far the directly analyzed content which indicates that the size and density fraction analyses seem to be reliable. 
Table 2. Factorial Design Tests Summary

\begin{tabular}{ccccccccc}
\hline Test & Feedrate & Reagent & Level & $\begin{array}{c}\text { V-notch } \\
\text { depth, } \\
\text { in. }\end{array}$ & $\begin{array}{c}\text { Feed } \\
\text { Ash \% }\end{array}$ & $\begin{array}{c}\text { Conc } \\
\text { Ash \% }\end{array}$ & $\begin{array}{c}\text { Tails } \\
\text { Ash \% }\end{array}$ & Yield \\
\hline 1 & $675(-)$ & Low & $2.7(+)$ & 12.42 & 11.23 & 5.89 & 40.59 & 84.61 \\
2 & $700(+)$ & High & $2.0(+)$ & 12.33 & 19.01 & 6.32 & 47.46 & 69.15 \\
3 & $700(+)$ & Low & $7.3(-)$ & 11.75 & 10.08 & 4.51 & 39.18 & 83.93 \\
4 & $560(-)$ & High & $5.8(-)$ & 11.50 & 13.50 & 5.15 & 45.96 & 79.54 \\
5 & $700(+)$ & Low & $1.9(+)$ & 12.50 & 14.56 & 5.17 & 41.17 & 73.92 \\
6 & Low (-) & High & $1.7(+)$ & 11.63 & 13.56 & 5.98 & 49.36 & 82.53 \\
7 & $660(-)$ & Low & $5.8(-)$ & & 14.94 & 4.82 & 40.38 & 71.54 \\
8 & $715(+)$ & High & $7.8(-)$ & 12.50 & 17.18 & 6.09 & 41.70 & 68.86 \\
9 & $715(0)$ & Normal & $4.0(0)$ & 12.75 & 22.40 & 4.55 & 45.66 & 56.58 \\
10 & $685(0)$ & Normal & $4.1(0)$ & 11.50 & 11.68 & 4.82 & 43.77 & 82.39 \\
\hline
\end{tabular}

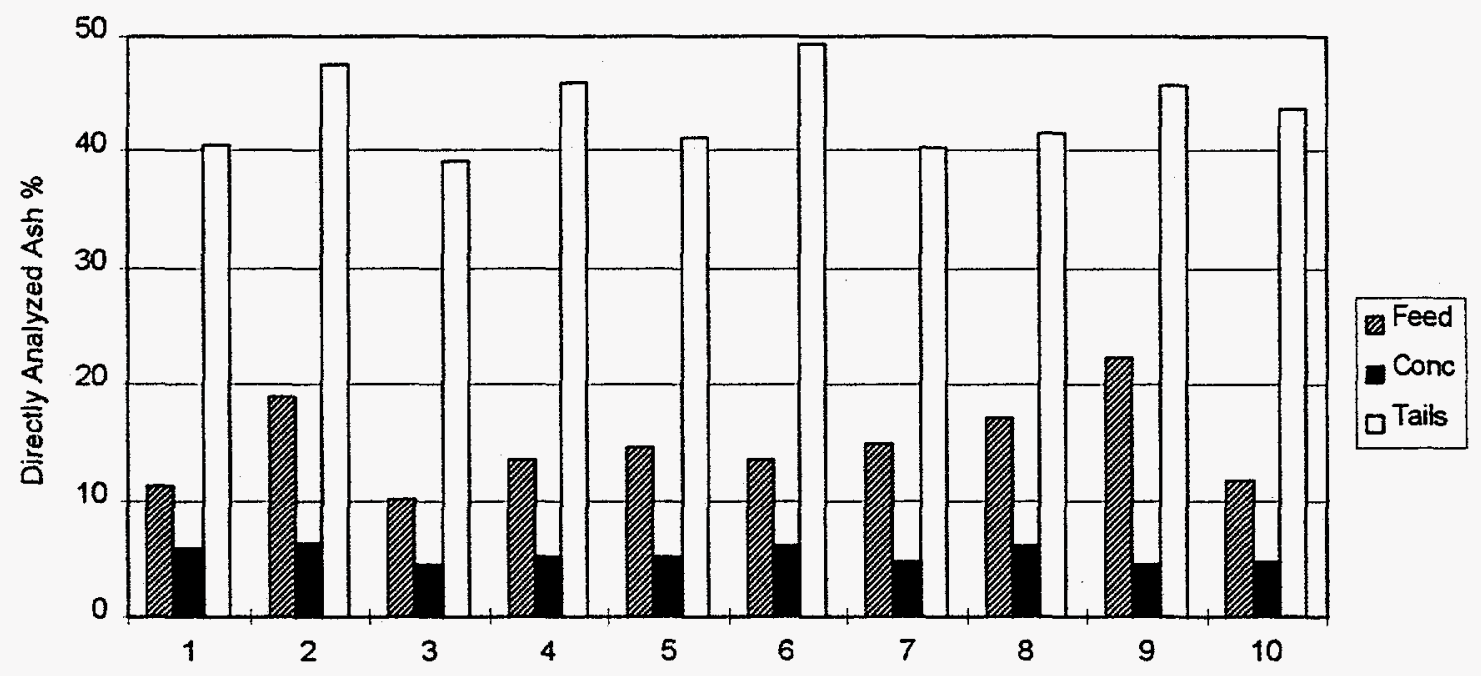

Figure 3. Ash percent for all tests. 
Table 3. Directly Measured and Computed Ash Percent

\begin{tabular}{ccccccccc}
\hline & \multicolumn{2}{c}{ Feed Ash \% } & \multicolumn{2}{c}{ Product Ash \% } & \multicolumn{2}{c}{ Tails Ash \% } & \multicolumn{2}{c}{ Yield } \\
Test & Direct & Computed & Direct & Computed & Direct & Computed & Direct & Computed \\
\hline 1 & 11.23 & 11.97 & 5.89 & 5.75 & 40.59 & 39.89 & 84.61 & 81.78 \\
2 & 19.01 & 19.75 & 6.32 & 6.49 & 47.46 & 46.50 & 69.15 & 66.86 \\
3 & 10.08 & 10.64 & 4.51 & 4.57 & 39.18 & 37.53 & 83.93 & 81.58 \\
4 & 13.50 & 13.86 & 5.15 & 5.28 & 45.96 & 47.22 & 79.54 & 79.54 \\
5 & 14.56 & & 5.17 & & 41.17 & & 73.92 & \\
6 & 13.56 & 13.83 & 5.98 & 5.91 & 49.36 & 47.80 & 82.53 & 81.08 \\
7 & 14.94 & 16.13 & 4.82 & 4.35 & 40.38 & 39.65 & 71.54 & 66.62 \\
8 & 17.18 & 16.43 & 6.09 & 5.67 & 41.70 & 43.29 & 68.86 & 71.41 \\
9 & 22.40 & 23.07 & 4.55 & 5.33 & 45.66 & 45.47 & 56.58 & 55.80 \\
10 & 11.68 & 13.07 & 4.82 & 5.10 & 43.77 & 45.58 & 82.39 & 80.31 \\
\hline
\end{tabular}

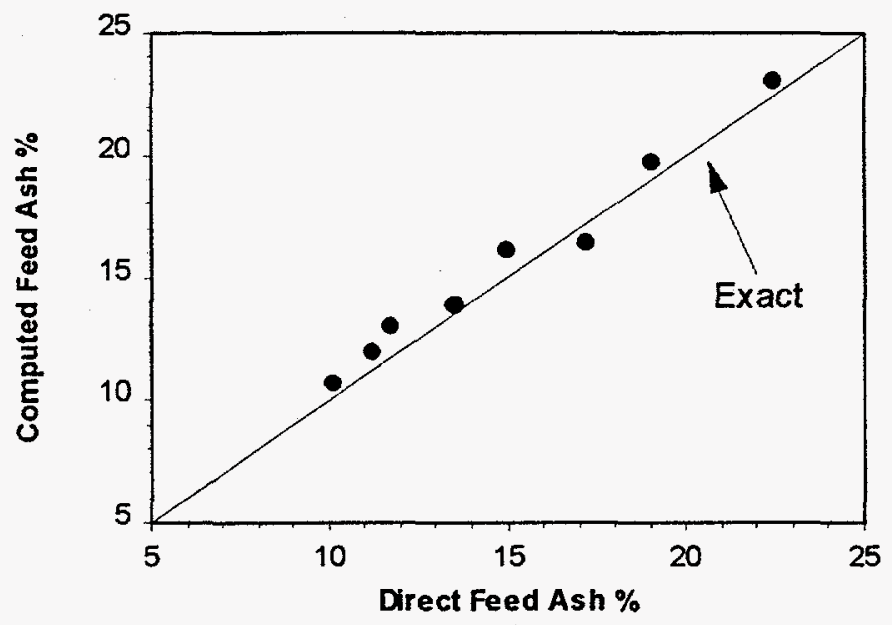

Figure 4 . Feed ash \% directly analyzed and indirectly computed. 


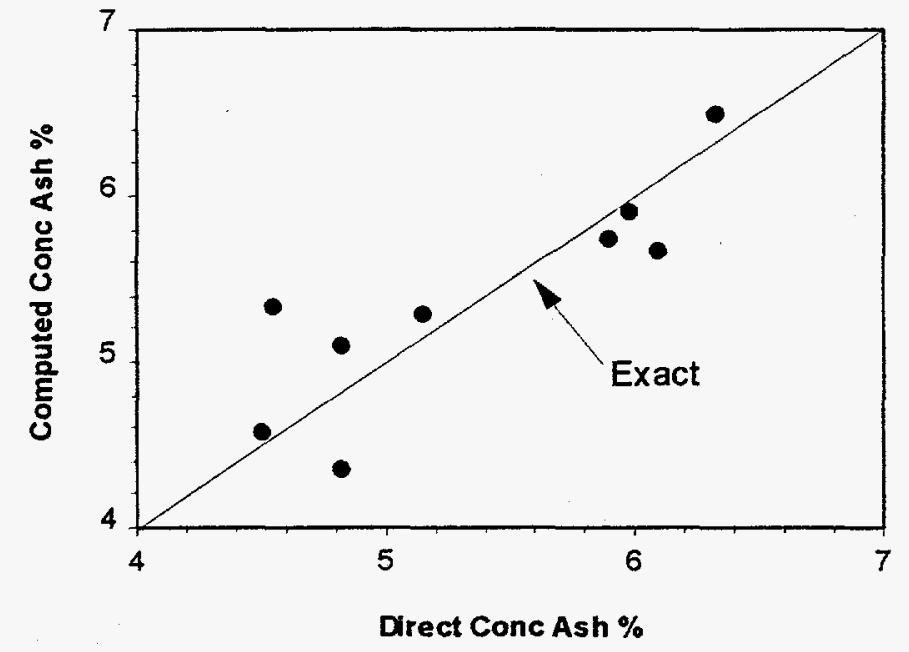

Figure 5. Concentrate ash \% directly analyzed and indirectly computed.

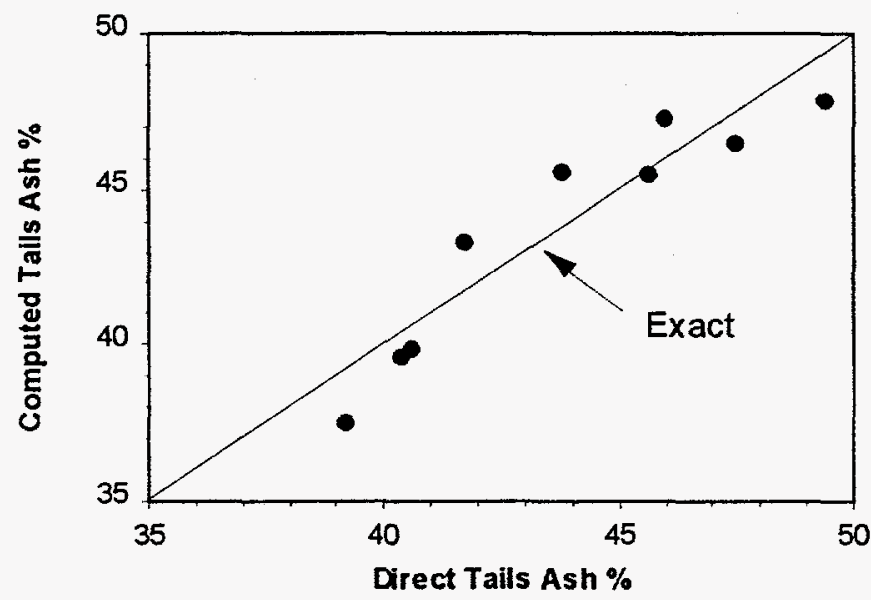

Figure 6. Tails ash \% directly analyzed and indirectly computed.

Residence Time Distribution. The impulse response of an $\mathrm{N}$-mixers-in-series vessel is given by

$$
\frac{C(t)}{C(0)}=\tau E(t)=\frac{N^{N}(t / \tau)^{N-1}}{\Gamma(N)} e^{-N(t / \tau)}
$$

where $C(t)$ is the concentration at exit of the vessel, $\mathrm{C}(0)$ is the concentration in the vessel at time $0, \mathrm{~N}$ is the number of mixers and is the residence time of the vessel. (The nominal residence time is $\tau=V / Q$.) 
Figure 7 shows the $\mathrm{Li}$ concentration response from the $1 \mathrm{~kg}$ impulse. Two curves are shown. The first is the best model fit, $N=2.1$, and the other , $N=3$, is the theoretical response if each of the three cells in the flotation bank behaved as single perfect mixers. The fact that the best fit is obtained with $N=2.1$ is a little troubling since the flotation simulator represents each cell as a single perfect mixer (to yield a 3-mixers-in-series residence time distribution for the simulated flotation bank). For the simulator to match the real world mixing characteristics the bank could be simulated by two flotation cells with a combined total volume and lip length equal to the real 3 cell flotation bank.

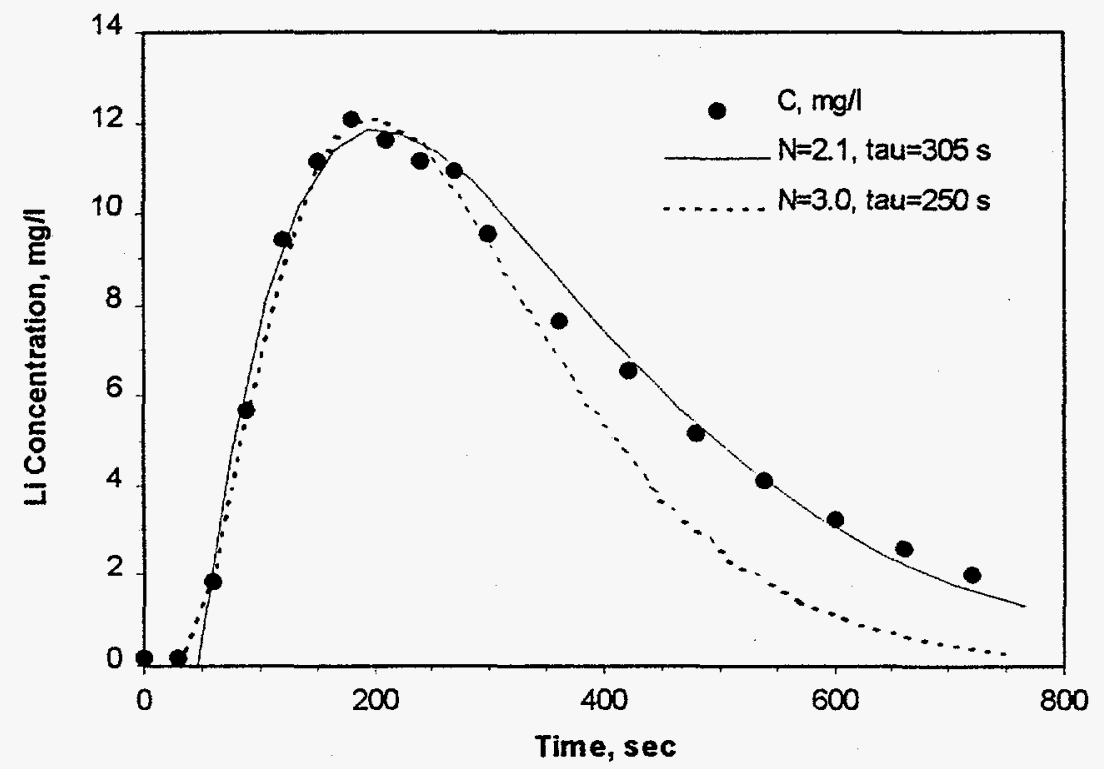

Figure 7. The experimental and fitted residence time distributions.

\section{Testwork and Analysis for the Video-Based Ash Analyzer}

Upon completion of the sampling campaign, additional samples of flotation feed, concentrate, and tailings were collected by VPI\&SU personnel throughout the quarter. Several of these samples were sized and ashed to determine the size-by-size ash content, while other samples were used in release analysis testing. The purpose of this work was to learn more about the characteristics of the mineral matter in the tailings and to determine if improvements in the performance of the flotation bank might lead to a higher-ash tailings that is more amenable to analysis by the video-based ash analyzer. 
Table 4 shows a size-by-size ash analysis conducted on a flotation tailings sample from the Maple Meadow plant. As shown, there is a considerable amount $(68 \%)$ of coarse $(+100 \mathrm{mesh})$ material in this sample. This number agrees well with the $60-65 \%+100$ mesh material reported for three other flotation tailings samples in the previous quarterly report. The large amount of coarse material raises some concerns about the utility of the video-based analyzer in this particular application, primarily because it is doubtful that this material ever makes it to the surface of the slurry in the sampling tube to be seen by the camera. It is also interesting to note that the distribution of ash appears to be relatively uniform as a function of particle size. This finding would tend to indicate that fine clays ( $-400 \mathrm{mesh})$ do not make a significant contribution to the overall ash content of this material. This characteristic would also tend to have a negative impact on the performance of the video-based ash analyzer, since the analyzer responds best to coals having an ash content that is primarily influenced by fine clays.

Table 4. Size-by-size ash analysis of Maple Meadow flotation tailings.

\begin{tabular}{ccc}
\hline Size $($ mesh $)$ & $\%$ Wt. & $\%$ Ash \\
\hline+28 & 21.41 & 66.04 \\
$28 \times 100$ & 46.47 & 71.23 \\
$100 \times 150$ & 4.64 & 69.39 \\
$150 \times 200$ & 3.02 & 67.02 \\
$200 \times 270$ & 2.45 & 62.89 \\
$270 \times 400$ & 1.76 & 53.73 \\
-400 & 20.25 & 63.76 \\
\hline Total & 100.00 & 67.88 \\
\hline
\end{tabular}

Table 5 shows the size-by-size analyses of feed, concentrate and tailings samples which were collected simultaneously in order to get a "snap shot" of the overall performance of the flotation circuit. As shown, all three streams are relatively coarse, containing $45-50 \%+100$ mesh material. At the same time, the amount of -400 mesh material varies from $20-30 \%$. Thus, the ash content in all three samples appears to be dominated by the coarse size fractions. The performance of the flotation circuit at this particular point in time appears to be quite good with an overall clean coal yield of $85.2 \%$ and a combustible recovery of $91.9 \%$. However, the low 
concentrate ash (4.7\%) would seem to indicate that the clean coal yield could be increased even further without exceeding the contract limitations on ash content.

Table 5. Size-by-size ash analyses of feed, concentrate and tailings samples.

\begin{tabular}{ccccccc}
\hline & \multicolumn{2}{c}{ Feed } & \multicolumn{2}{c}{ Concentrate } & \multicolumn{2}{c}{ Tailing } \\
Size & $\% \mathrm{Wt}$. & $\%$ Ash & \% Wt. & $\%$ Ash & $\%$ Wt. & $\%$ Ash \\
$(\mathrm{mesh})$ & & & & & & \\
\hline+28 & 5.4 & 8.7 & 8.11 & 2.5 & 10.81 & 41.7 \\
$28 \times 100$ & 40.3 & 7.9 & 38.0 & 3.0 & 37.6 & 50.6 \\
$100 \times 150$ & 10.8 & 8.7 & 12.3 & 3.8 & 6.6 & 54.0 \\
$150 \times 200$ & 7.1 & 9.9 & 7.6 & 4.8 & 50.0 & \\
$200 \times 270$ & 6.7 & 11.9 & 7.8 & 5.1 & 4.4 & 49.1 \\
$270 \times 400$ & 5.3 & 10.1 & 6.0 & 4.8 & 3.5 & 44.9 \\
-400 & 24.4 & 20.3 & 20.2 & 9.4 & 32.3 & 56.3 \\
Total & 100.0 & 11.6 & 100.0 & 4.7 & 100.0 & 51.4
\end{tabular}

Yield $=85.2 \%$

Combustible Recovery $=91.9 \%$

Additional room for improvement in the flotation circuit performance is also seen in the release analysis data shown in Table 6 and Figure 8. As shown, release analysis of the feed sample indicates that it is theoretically possible to produce a product containing $4.4 \%$ ash at an $89 \%$ yield. An examination of the release curve for the feed indicates that it should be possible to obtain a product containing less than $6 \%$ ash at a yield of $93-94 \%$. This would correspond to adding the first three increments of tailings sample no. 1 or the first two increments of tailings sample no. 2 to the $4.4 \%$ ash product from the original release test conducted on the feed. Thus, if the goal is to obtain a $6 \%$ ash product, it appears that approximately $20-50 \%$ of the tailings material is being misplaced and should be recovered with the product.

In summary, the size-by-size analysis and the release analysis testing seem to indicate that the ash in the Maple Meadow flotation samples is dominated by the +100 mesh material. The overall flotation performance is good, but it appears that there is room for improvement. Overall clean coal yield could be increased by $5-10 \%$ while still maintaining an ash content below $6 \%$. In the absence of process control it appears that the flotation circuit is currently operated in a conservative manner to ensure that contract specifications are achieved. At present, the 
relatively low ash content of the tailings material and the coarse particle size would tend to make video ash analysis difficult. However, improvements in the performance of the flotation circuit may produce tailings ash contents in the range of $70-80 \%$. Under these conditions, the ash analyzer has been shown to be more promising in current applications at the Middle Fork preparation plant operated by Pittston Coal Company.

Table 6. Release analysis test results

\begin{tabular}{ccccc}
\hline Stream & $\begin{array}{c}\text { Individual } \\
\text { \% Yield }\end{array}$ & \% Ash & $\begin{array}{c}\text { Cumulative } \\
\text { \% Yield }\end{array}$ & \% Ash \\
\hline Tailings Sample \#1 & & & & \\
Concentrate \#1 & 13.55 & 4.92 & 13.55 & 4.92 \\
Concentrate \#2 & 22.27 & 15.35 & 35.82 & 11.40 \\
Concentrate \#3 & 17.07 & 32.22 & 52.88 & 18.12 \\
Concentrate \#4 & 2.63 & 63.07 & 55.51 & 20.25 \\
Tailings & 44.49 & 83.33 & 100.00 & 48.31 \\
Tailings Sample \#2 & & & & \\
Concentrate \#1 & 8.97 & 19.80 & 8.97 & 19.80 \\
Concentrate \#2 & 8.58 & 27.12 & 17.55 & 23.38 \\
Concentrate \#3 & 4.04 & 39.22 & 21.59 & 26.34 \\
Concentrate \#4 & 1.33 & 55.10 & 22.92 & 28.01 \\
Tailings & 77.08 & 80.28 & 100.00 & 68.30 \\
Feed Sample & & & & \\
Concentrate \#1 & 35.83 & 2.80 & 35.83 & 2.80 \\
Concentrate \#2 & 36.78 & 4.58 & 72.61 & 3.70 \\
Concentrate \#3 & 13.69 & 6.55 & 86.31 & 4.15 \\
Concentrate \#4 & 2.70 & 10.92 & 89.01 & 4.36 \\
Tailings & 10.99 & 75.17 & 100.00 & 12.14 \\
\hline
\end{tabular}




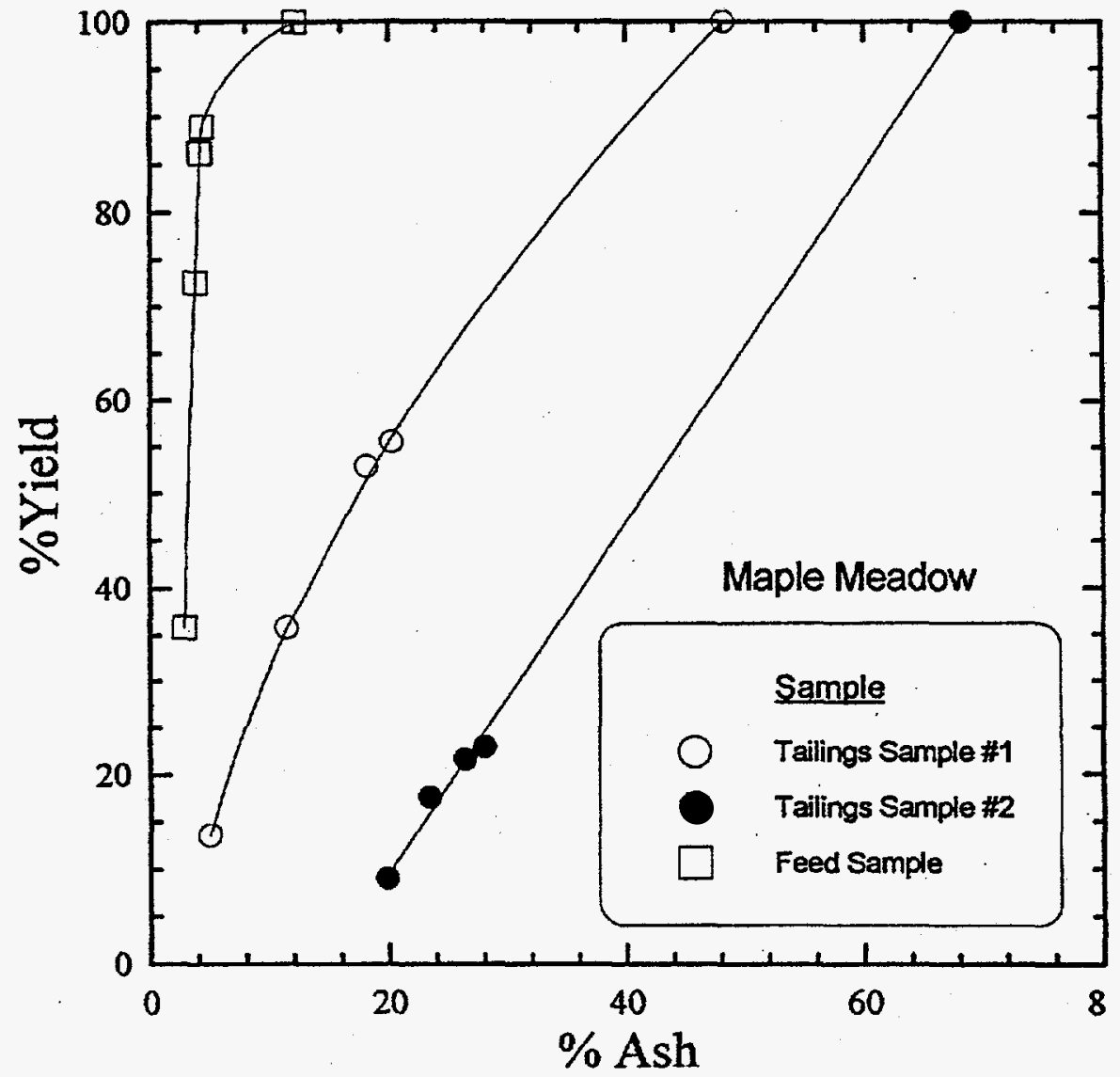

Figure 8. Results of release analysis tests performed on two tailings samples and one feed sample from the Maple Meadow preparation plant.

\section{Task 3 - Modeling and Simulation}

Subtask 3.1 - Model Building. The model for the flotation is represented schematically in Figure 9. Particles of size $d_{i}$ and composition (density) $\rho_{j}$ exist in four possible states 1 ) free in the pulp, 2) attached to bubbles in the pulp, 3) free in the liquid in the froth and 4) attached to bubbles in the froth. The properties of greatest important in flotation are size and composition. The number of particles of size $i$ and mineralogical composition $j$ per unit volume in one of the four possible states is denoted by $\psi_{i j}$. The interphase transfer rates, denoted by $k$, are shown. 


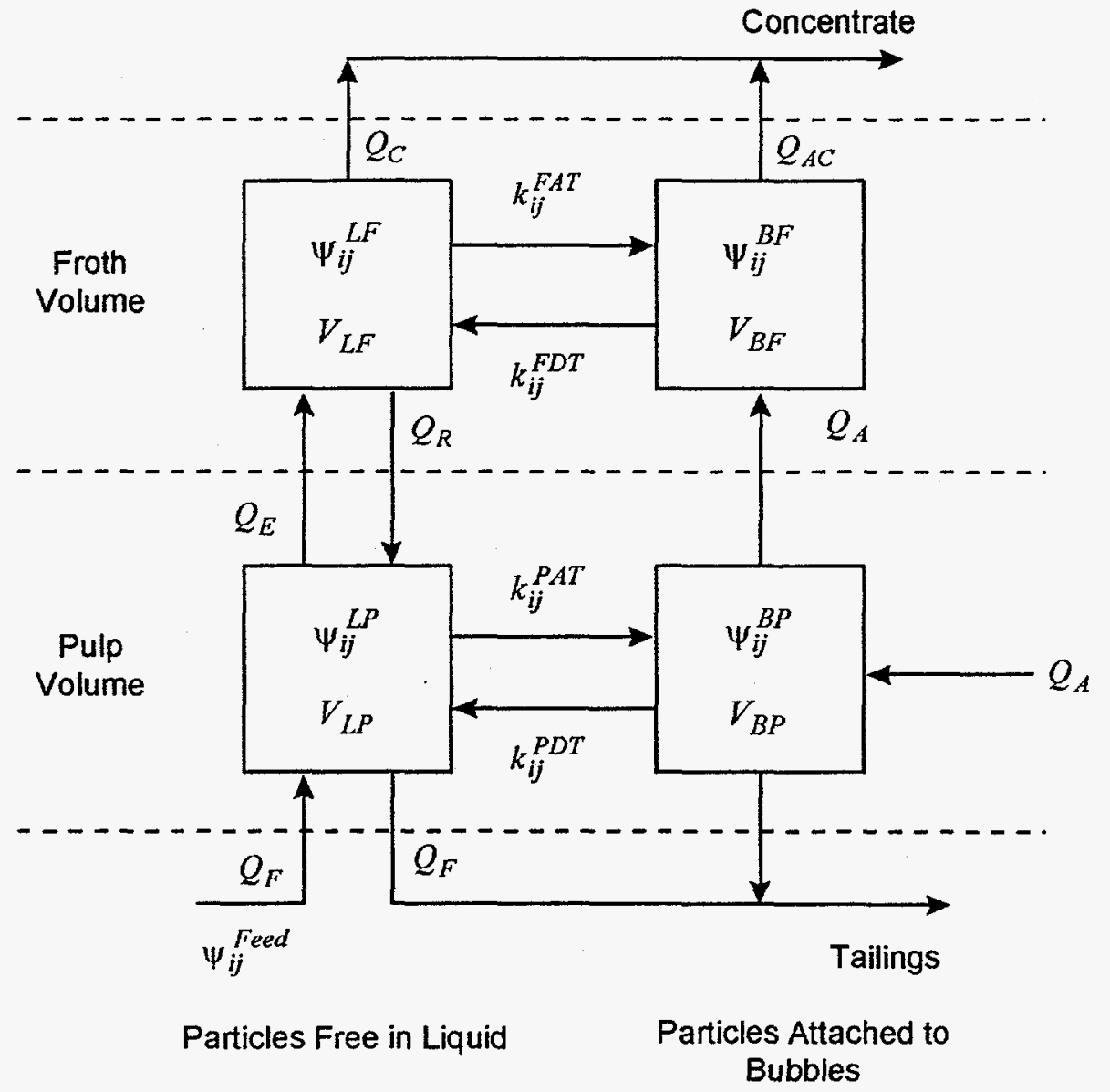

Figure 9. Four states for particles in a flotation cell.

The population balance model framework is an approach to the modeling of particulate systems that can not be solved using the usual continuity of mass and rate expressions. A number balance is developed from the general conservation equation:

accumulation $=$ input - output + net generation

applied to particles having a specified set of properties $\left\{\zeta_{1}, \zeta_{2}, \ldots, \zeta_{J}\right\}$. In this balance, input and output terms represent changes in the number of particles in the specified property intervals resulting from convective flow, while the generation term accounts for particles entering and leaving the specified property intervals as a result of individual kinetics such as a change of state depicted in Figure 9.

The macroscopic form of the population balance model is applicable when the vessel is to a first approximation well mixed or when residence time distribution information is available. 
The overall number balance of particles of size $i$ and mineralogical species $j$ for each of the four possible states are:

Free in pulp

$$
\frac{d}{d t}\left(V_{L P} \Psi_{i j}^{L P}\right)+k_{i j}^{P A T} V_{L P} \psi_{i j}^{L P}-k_{i j}^{P D T} V_{B P} \psi_{i j}^{B P}=Q_{F e e d} \psi_{i j}^{F e e d}-Q_{T} \psi_{i j}^{L P}+Q_{R} k_{i j}^{R} \psi_{i j}^{L F}-Q_{E} \psi_{i j}^{L P}
$$

Attached in pulp

$$
\frac{d}{d t}\left(V_{B P} \psi_{i j}^{B P}\right)+k_{i j}^{P D T} V_{B P} \psi_{i j}^{B P}-k_{i j}^{P A T} V_{L P} \psi_{i j}^{L P}=Q_{A} \psi_{i j}^{B P}-Q_{A T} \psi_{i j}^{B P}
$$

Free in froth

$$
\frac{d}{d t}\left(V_{L F} \psi_{i j}^{L F}\right)+k_{i j}^{F A T} V_{L F} \psi_{i j}^{L F}-k_{i j}^{F D T} V_{B F} \psi_{i j}^{B F}=Q_{E} \psi_{i j}^{L P}-Q_{C} \psi_{i j}^{L F}-Q_{R} k_{i j}^{R} \psi_{i j}^{L F}
$$

Attached in the froth

$$
\frac{d}{d t}\left(V_{B F} \psi_{i j}^{B F}\right)+k_{i j}^{F D T} V_{B F} \psi_{i j}^{B F}-k_{i j}^{F A T} V_{L F} \psi_{i j}^{L F}=Q_{A} \psi_{i j}^{B P}-Q_{A C} \psi_{i j}^{B F}
$$

where $\psi_{i j}^{L P}$ is the number of particles free in the liquid in the pulp of size $i$ and mineralogical species $j$ per volume of liquid in the pulp, $\psi_{i j}^{B P}$ is the number of particles attached to bubbles in the pulp of size $i$ and mineralogical species $j$ per unit volume of air in the pulp, $\psi_{i j}^{L F}$ is the number of particles free in the liquid in the froth of size $i$ and mineralogical species $j$ per unit volume of liquid in the froth, $\psi_{i j}^{B F}$ is the number of particles attached to bubbles in the froth of size $i$ and mineralogical species $j$ per unit volume of air in the froth and $\psi_{i j}^{F e e d}$ is the number of particles of size $i$ and mineral species $j$ per unit volume of liquid.

The interphase transfer rates are dependent on particle properties and the chemical and physical environment of the flotation cell where $k_{i j}^{P A T}$ is the particle attachment rate in the pulp, $k_{i j}^{P D T}$ is the particle detachment rate constant in the pulp, $k_{i j}^{F A T}$ is the particle attachment rate in the froth and $k_{i j}^{F D T}$ is the particle attachment rate in the froth. 
The input flows to the liquid volume are: 1) the feed of particles into the flotation cell; $Q_{F} \psi_{i j}^{\text {Feed }}$ where $Q_{F}$ is the liquid volume flowrate and 2) the return flow rate of particles draining from the froth carried by the water $Q_{R} k_{i j}^{R} \psi_{i j}^{L F}$ where $Q_{R}$ is the volumetric flowrate of water draining from the froth, $k_{i j}^{R}$ is a dimensionless classification constant representing the segregation mechanism that occurs in the draining liquid in the froth.

The output flows are: 1) the flowrate of particles leaving through the tailing port of the flotation cell $Q_{T} \psi_{i j}^{L P}$, where $Q_{T}$ is volumetric flowrate of liquid in the tails, and 2) the flowrate of particles entrained by the water flow, $Q_{E} \psi_{i j}^{L P}$, where $Q_{E}$ is the volumetric flowrate of water to the froth transported in the bubble film and wake.

\section{Task 4 - Sensor Development and Testing}

Subtask 4.1 - Calibration Testing: The purpose of this task is to establish calibration relationships for the video-based slurry analyzer, being developed under U.S. DOE Grant DEFG22-94PC94226, and to verify the appropriate means of sample presentation and lighting to be used in the analysis. The data obtained from the calibration testing will be used to establish the operating range, degree of resolution, accuracy and reproducibility of the optical analysis technique. For details on the design and construction of the video-based slurry analyzer, the reader is referred to the quarterly reports from U.S. DOE Grant DE-FG22-94PC94226.

During the past quarter, five sampling visits to the Maple Meadow coal preparation plant were made for the purpose of acquiring data for the testing and calibration of the video-based ash analyzer. In addition to the two visits from the previous quarter, there have now been a total of seven site visits thus far. For the purpose of discussion, these visits will be referenced by number beginning with plant visit no. 3 .

Plant visit no. 3 was carried out in early April primarily to check on the installation of the Vnotch weir box prior to the detailed plant sampling campaign (Subtask 2.1); however, at the same time an attempt was made to collect samples for calibrating the video sensor. Unfortunately, fluctuations in the plant power supply appeared to affect the illumination in the sampling tube to such an extent that the data were deemed unusable. 
In an attempt to compensate for the fluctuating power supply, a subsequent site visit (plant visit no. 4) was carried out in which the light intensity was adjusted to maintain a constant output from the photocell situated inside the sampling tube. The data obtained from this visit are shown in Table 7 and are plotted in Figure 10 along with the data previously obtained during plant visit no. 1 . As shown, there is clearly a trend indicating that the mean gray level of the sample increases as the ash content increases; however, the data are subject to considerable scatter. In fact, less than $70 \%$ of the points fall within $+5 \%$ ash of the best fit line through the data. The slope of the line indicates a resolution of $0.77 \%$ ash per gray level. Although this is not as good as has been achieved at the Middle Fork preparation plant $(0.46 \%$ ash per gray level), it is probably sufficient provided that the accuracy of the sensor, as indicated by the data scatter, can be improved.

Table 7. Video sensor calibration data from plant visit \#4

\begin{tabular}{cccc}
\hline $\begin{array}{c}\text { Sample } \\
\text { Number }\end{array}$ & $\begin{array}{c}\text { Percent } \\
\text { Solids }\end{array}$ & $\begin{array}{c}\text { Percent } \\
\text { Ash }\end{array}$ & $\begin{array}{c}\text { Mean Gray } \\
\text { Level }\end{array}$ \\
\hline 1 & 2.95 & 51.81 & 82.17 \\
2 & 3.61 & 49.76 & 66.97 \\
3 & 2.98 & 53.36 & 50.67 \\
4 & 3.35 & 47.74 & 46.84 \\
5 & 2.05 & 41.45 & 50.33 \\
6 & 4.50 & 48.26 & 49.19 \\
7 & 376 & 47.56 & 60.68 \\
8 & 3.84 & 47.66 & 55.04 \\
9 & 3.23 & 48.56 & 73.7 \\
10 & 3.04 & 47.88 & 47.09 \\
11 & 3.13 & 47.17 & 66.17 \\
12 & 3.03 & 48.03 & 63.48 \\
13 & 3.07 & 45.03 & 63.46 \\
14 & 3.64 & 46.93 & 60.35 \\
15 & 2.96 & 43.45 & 62.62 \\
16 & 2.78 & 52.03 & 64.43 \\
17 & 3.60 & 52.85 & 74.56 \\
\hline
\end{tabular}

Since power fluctuations are a common occurrence at any operating preparation plant, and since constant illumination is a key component in a video-based sensor, a modified sample tube was developed which incorporated a gray-level standard within the image. The details of the 
modified design are described under Subtask 4.2. The modified sample tube was tested during plant visit no. 5 to determine if the standard could be used to compensate for variations in the light intensity. The data obtained from this site visit are shown in Table 8 and Figure 11.

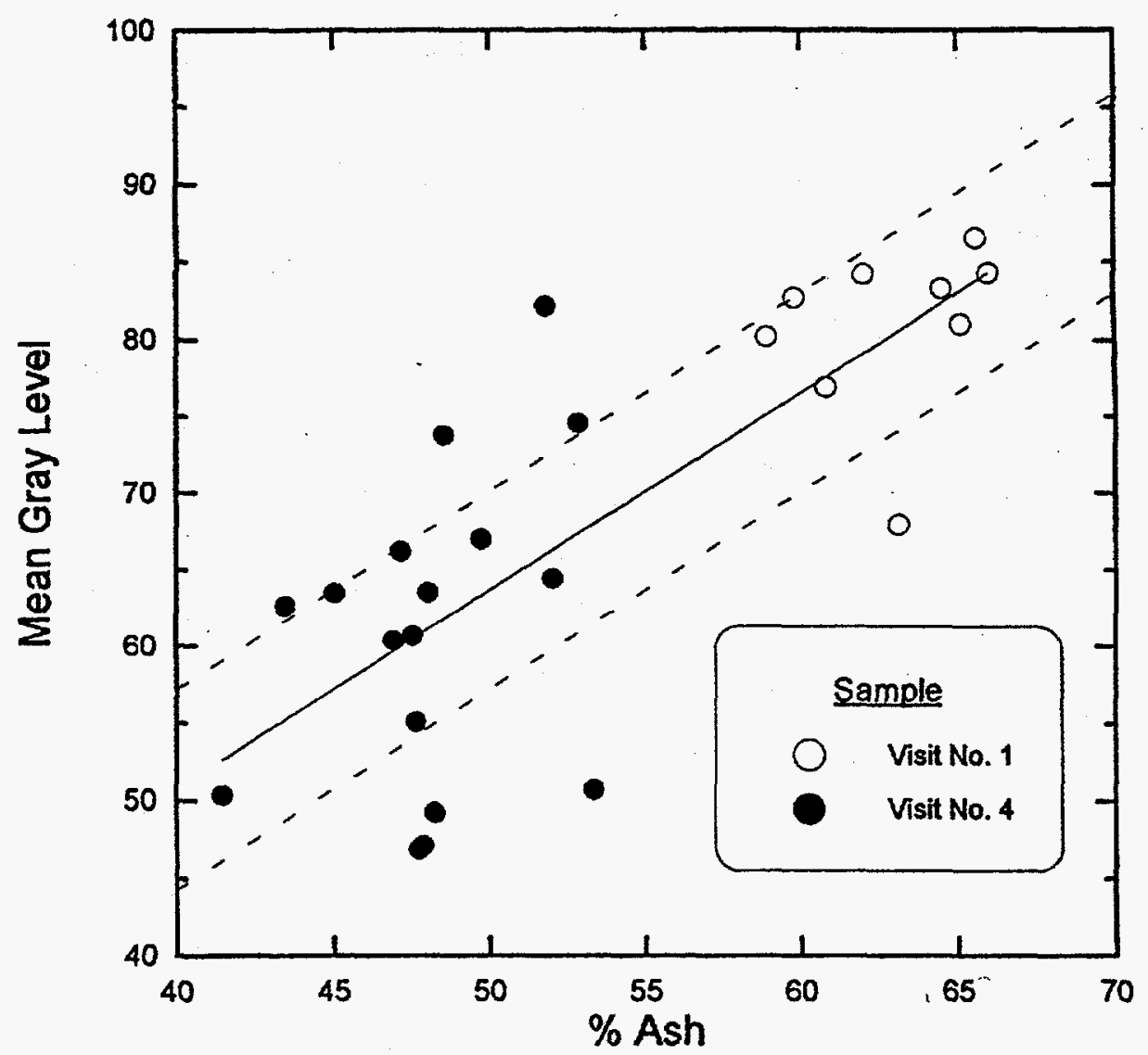

Figure 10. Video sensor calibration curve obtained from plant visits \#1 and \#4. The error bar indicates $\pm 5 \%$ ash.

As shown in Table 8, the mean-gray-level values for the standard were found to continually drift downward as a function of time, indicating that the sample illumination was decreasing. This phenomenon produced an artificial inverse relationship between mean gray level and ash content, as shown in Figure 11. It should be noted that all gray levels were higher for this set of data than in previous data due to the fact that the light intensity was increased in order to see if increased illumination would provide better resolution on this relatively low-ash tailings material. 
In order to correct for the drifting light intensity, the percentage change in the mean gray level of the standard (relative to measurement no. 1) was used to adjust the mean-gray-level values of the sample. These normalized values are shown in the last column of Table 8 and are plotted in Figure 11. As shown, the trend in the data is now as expected although the data scatter is significant. The resolution of this calibration curve, as indicated by the slope, is nearly identical to that shown in Figure 10; however, only about half of the data points lie within $+5 \%$ ash of the best fit line.

Table 8. Video sensor calibration data for plant visit \#5

\begin{tabular}{cccccc}
\hline Sample & \% Solids & \% Ash & $\begin{array}{c}\text { MGL } \\
\text { (Sample) }\end{array}$ & $\begin{array}{c}\text { MGL } \\
\text { (Sample) }\end{array}$ & $\begin{array}{c}\text { Normalized } \\
\text { MGL }\end{array}$ \\
\hline 1 & 3.33 & 45.77 & 89.2 & 206.6 & 89.2 \\
2 & 390 & 44.44 & 88.3 & 206.8 & 88.2 \\
3 & 3.97 & 39.37 & 86.8 & 204.2 & 87.8 \\
4 & 3.83 & 41.10 & 86.1 & 195.6 & 90.9 \\
5 & 3.87 & 43.47 & 84.6 & 180.2 & 97.0 \\
6 & 3.49 & 41.97 & 84.0 & 181.3 & 95.7 \\
7 & 3.63 & 48.40 & 79.9 & 176.9 & 93.3 \\
8 & 3.18 & 43.48 & 80.2 & 177.2 & 93.5 \\
9 & 3.31 & 44.98 & 80.1 & 167.2 & 99.0 \\
10 & 3.49 & 47.74 & 74.5 & 143.3 & 107.4 \\
11 & 3.46 & 44.04 & 73.0 & 118.8 & 127.0 \\
12 & 3.37 & 47.99 & 72.4 & 139.3 & 107.4 \\
13 & 3.52 & 50.19 & 63.4 & 133.6 & 98.0 \\
14 & 3.59 & 47.23 & 84.7 & 154.3 & 113.4 \\
15 & 3.34 & 43.40 & 85.3 & 149.0 & 118.3 \\
16 & 3.52 & 49.78 & 86.2 & 153.5 & 116.0 \\
17 & 3.42 & 45.68 & 83.0 & 152.2 & 112.7 \\
18 & 319 & 45.06 & 74.3 & 132.2 & 116.1 \\
\hline
\end{tabular}




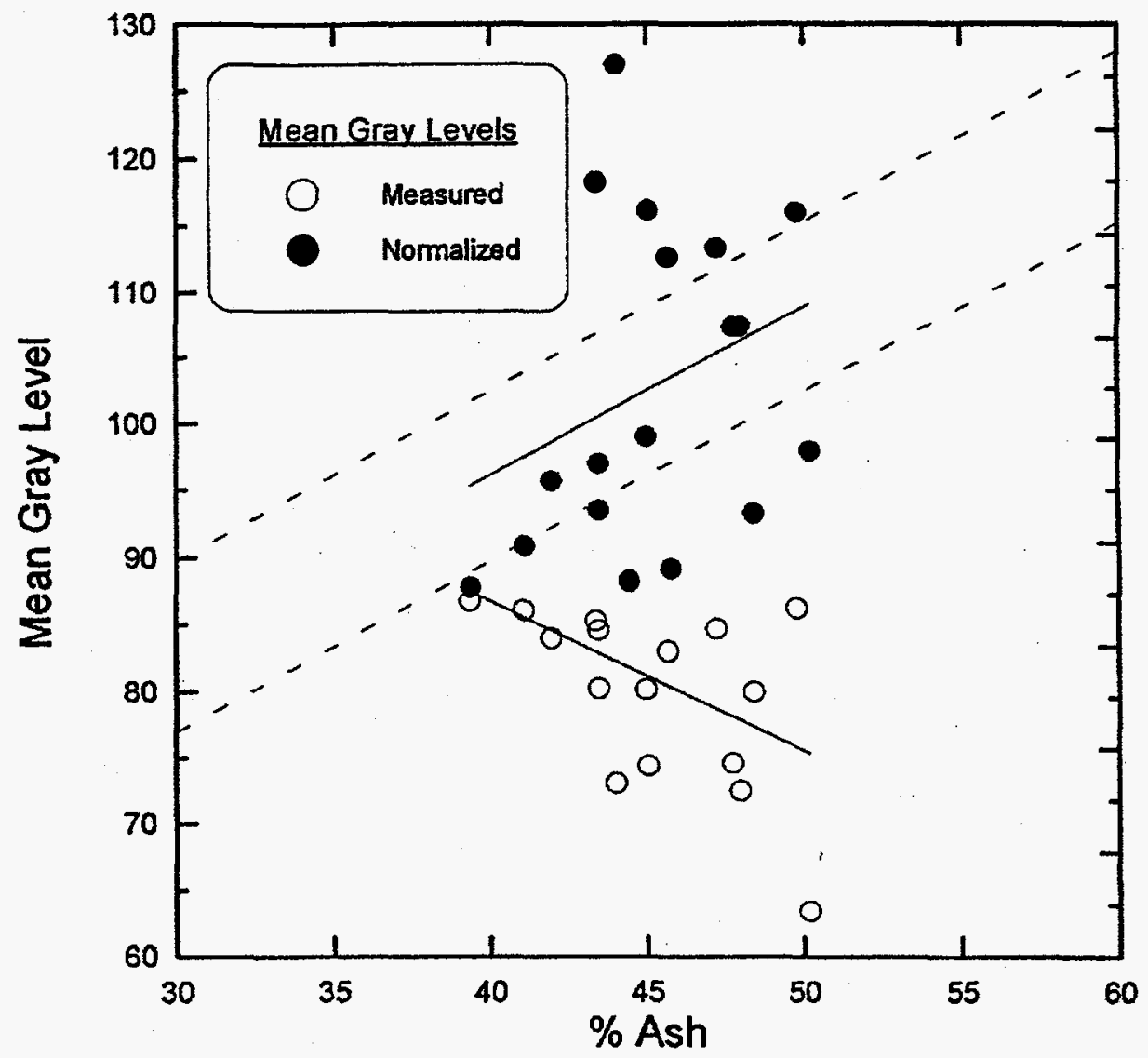

Figure 11. Video sensor calibration curve obtained from plant visit \#5 showing the original data "as measured" and the data normalized using a standard. The error bar indicates $\pm 5 \%$ ash.

Following the analysis of the data from plant visit no. 5 , it was clear that there were too many variations in conditions at the plant to determine whether or not it was possible to use the video-based ash analyzer in this particular application. Therefore, sixteen samples were collected in plant visit no. 6 and brought back to VPI\&SU for analysis under controlled conditions. The data from this work is shown in Table 9. As shown, the tailings ash was very low on this particular occasion, ranging from $30-37 \%$. Thus, the samples were not appropriate for obtaining a calibration curve; however, they were suitable for examining the behavior of the light standard and its use in normalizing the mean-gray-level data. 
Table 9. Video sensor calibration data for plant visit \#6.

\begin{tabular}{|c|c|c|c|c|c|c|c|c|c|}
\hline \multirow[b]{2}{*}{ Sample } & \multirow[b]{2}{*}{$\%$ Ash } & \multicolumn{2}{|c|}{ Constant Illumination } & \multicolumn{2}{|c|}{ Variable Illumination } & \multicolumn{4}{|c|}{ Normalization } \\
\hline & & $\begin{array}{c}\text { MGL } \\
\text { (Sample) }\end{array}$ & $\begin{array}{c}\text { MGL } \\
\text { (Standard) }\end{array}$ & $\begin{array}{c}\text { MGL } \\
\text { (Sample) }\end{array}$ & $\begin{array}{c}\text { MGL } \\
\text { (Standard) }\end{array}$ & $\begin{array}{l}\text { Delta MGL } \\
\text { Sample } \\
\text { (Absolute) }\end{array}$ & $\begin{array}{l}\text { Delta MGL } \\
\text { Standard } \\
\text { (Absolute) }\end{array}$ & $\begin{array}{l}\text { Delta MGL } \\
\text { Sample } \\
\text { (Percent) }\end{array}$ & $\begin{array}{l}\text { Delta MGL } \\
\text { Standard } \\
\text { (Percent) }\end{array}$ \\
\hline 1 & 32.0 & 107.8 & 209.2 & 123.3 & 221.4 & 15.5 & 12.2 & 14.4 & 5.8 \\
\hline 2 & 34.0 & 113.8 & $207 . \mathrm{g}$ & 95.0 & 192.4 & 18.8 & 15.4 & 16.5 & 7.4 \\
\hline 3 & 35.5 & 113.9 & 209.6 & 134.0 & 225.2 & 20.1 & 15.6 & 17.6 & 7.4 \\
\hline 4 & 34.1 & 120.6 & 212.4 & 104.6 & 199.5 & 16.0 & 12.9 & 13.3 & 6.1 \\
\hline 5 & 30.7 & 129.6 & 209.2 & 146.1 & 225.3 & 16.5 & 16.1 & 12.7 & 7.7 \\
\hline 6 & 33.1 & 133.3 & 213.9 & 113.0 & 199.9 & 20.3 & 14.0 & 15.2 & 6.5 \\
\hline 7 & 36.5 & 133.8 & 210.4 & 145.1 & 222.2 & 11.3 & 11.8 & 8.4 & 5.6 \\
\hline 8 & 35.8 & 140.1 & 217.9 & 124.5 & 207.5 & 15.6 & 10.4 & 11.1 & 4.8 \\
\hline 9 & 36.5 & 130.6 & 209.9 & 142.4 & 219.6 & 11.8 & 9.7 & 9.0 & 4.6 \\
\hline 10 & 31.4 & 142.9 & 210.9 & 127.6 & 201.9 & 15.3 & 9.0 & 10.7 & 4.3 \\
\hline 11 & 31.9 & 141.2 & 215.1 & 152.5 & 223.8 & 11.3 & 8.7 & 8.0 & 4.0 \\
\hline 12 & 34.7 & 152.2 & 212.4 & 134.5 & 201.4 & 17.7 & 11.0 & 11.6 & 5.2 \\
\hline 13 & 34.9 & 143.3 & 210.9 & 149.6 & 216.0 & 6.3 & 5.1 & 4.4 & 2.4 \\
\hline 14 & 32.6 & 145.0 & 211.2 & 120.4 & 189.4 & 24.6 & 21.8 & 17.0 & 10.3 \\
\hline 15 & 30.8 & 154.5 & 212.0 & 161.6 & 222.3 & 7.1 & 10.3 & 4.6 & 4.9 \\
\hline 16 & 30.1 & 149.9 & 211.7 & 136.4 & 201.5 & 13.5 & 10.2 & 9.0 & 4.8 \\
\hline
\end{tabular}

In order to investigate the behavior of the gray-level standard, the mean gray level of each sample was determined under relatively constant lighting conditions. The same set of samples was then analyzed with the light intensity purposely varied in a random manner to simulate fluctuations in the power supply. The absolute difference and the percentage difference in the mean gray level of the sample and the standard were then calculated and plotted in Figure 12. A straight line with a slope of unity and an intercept of zero would indicate an exact correlation between the change in the standard gray level and the sample gray level.

As shown in Figure 12, the relationship between the standard and the sample, in terms of the absolute difference in gray level, results in a straight line with a slope of unity; however, the intercept is approximately 3 , indicating that the difference in the mean gray level of the sample is offset from the difference in the mean gray level of the standard by three gray levels. In terms of the percentage difference, the line has an intercept of zero, but the slope is approximately two, indicating that a change in the mean gray level of the sample is approximately twice that of the standard. In other words, the sample is more sensitive to changes in incident light than is the standard. 


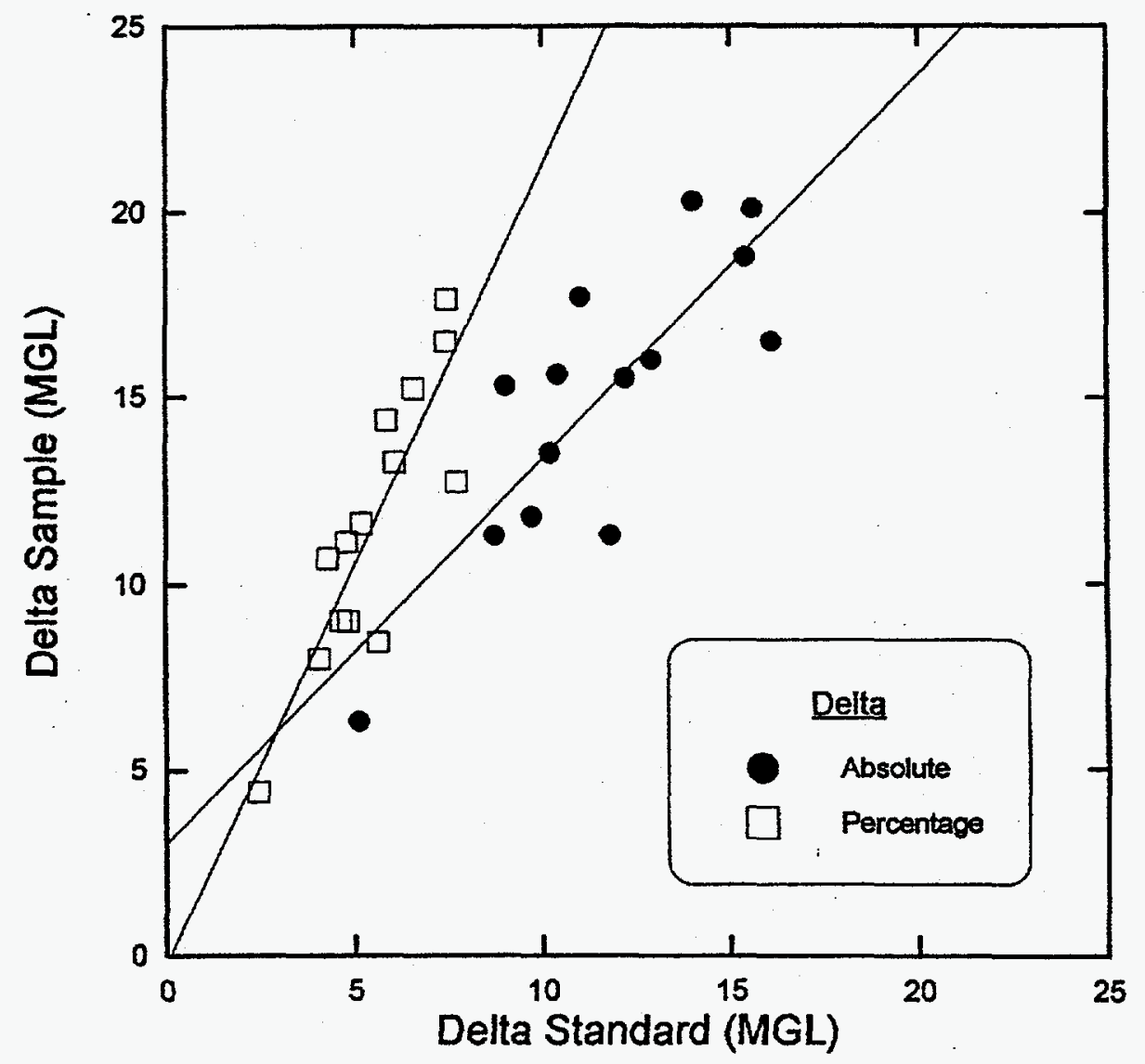

Figure 12. Comparison of the change in the mean gray level of the standard and the sample on an absolute and a percentage basis.

Of the two normalization techniques, the percentage method seems to be the best procedure since this approach exhibits less scatter in the data and produces no change in the sample mean gray level when there is no change in the standard mean gray level. As shown in Table 10, when the data obtained under variable illumination is normalized with both techniques, the percentage normalization procedure seems to do the best job of reproducing the gray levels measured under constant illumination. 
Table 10. Gray level normalization data for plant visit \#6.

\begin{tabular}{cccccc}
\hline Sample & \%Ash & MGL & MGL & $\begin{array}{c}\text { Normalized } \\
\text { MGL }\end{array}$ & $\begin{array}{c}\text { Normalized } \\
\text { MGL }\end{array}$ \\
\hline 1 & 32.0 & 107.8 & 123.3 & 114.1 & 108.7 \\
2 & 34.0 & 113.8 & 95.0 & 113.4 & 116.4 \\
3 & 35.5 & 113.9 & 134.0 & 121.4 & 114.4 \\
4 & 34.1 & 120.6 & 104.6 & 120.5 & 117.8 \\
5 & 30.7 & 129.6 & 146.1 & 133.0 & 130.6 \\
6 & 33.1 & 133.3 & 113.0 & 130.0 & 128.3 \\
7 & 36.5 & 133.8 & 145.1 & 136.3 & 133.3 \\
8 & 35.8 & 140.1 & 124.5 & 137.9 & 129.8 \\
9 & 36.5 & 130.6 & 142.4 & 135.7 & 130.7 \\
10 & 31.4 & 142.9 & 127.6 & 139.6 & 141.6 \\
11 & 31.9 & 141.2 & 152.5 & 146.8 & 134.3 \\
12 & 34.7 & 152.2 & 134.5 & 148.5 & 148.6 \\
13 & 34.9 & 143.3 & 149.6 & 147.5 & 142.0 \\
14 & 32.6 & 145.0 & 120.4 & 145.2 & 143.3 \\
15 & 30.8 & 154.5 & 161.6 & 154.3 & 151.5 \\
16 & 30.1 & 149.9 & 136.4 & 149.6 & 147.4 \\
\hline
\end{tabular}

Following the studies on gray-level normalization, a seventh plant visit was made to collect samples over a wide range of ash contents which could be used for calibrating the sensor. The samples were brought back to VPI\&SU for analysis under controlled conditions. The gray-level data obtained from plant visit no. 7 were then combined with the previous values from plant visit no. 6 to obtain a calibration curve. These data are shown in Table 11 and Figures 13 and 14 .

As shown in Figure 13, the original ("as measured") gray-level values clearly show a trend of increasing gray level with increasing ash content. Unfortunately, the data scatter is significant. After the data are normalized (Figure 14), the scatter is reduced slightly, but it is still too great to provide a reliable measure of slurry ash content. In both cases, only half of the data points lie within $+5 \%$ ash of the calibration line; although the resolution of the calibration curve is approximately $1.0 \%$ ash per gray-level increment. Thus, the video-based ash analyzer would be satisfactory in this application if the accuracy were improved. 
Table 11. Video sensor calibration data for plant visits \#6 and \#7

\begin{tabular}{|c|c|c|c|c|}
\hline Sample & $\%$ Ash & Sample MGL & Standard MGL & $\begin{array}{c}\text { Normalized } \\
\text { MGL }\end{array}$ \\
\hline \multicolumn{5}{|c|}{ Visit No. 6} \\
\hline 1 & 32.01 & 107.81 & 209.21 & 108.7 \\
\hline 2 & 34.0 & 113.8 & 207.8 & 116.4 \\
\hline 3 & 35.5 & 113.9 & 209.6 & 114.4 \\
\hline 4 & 34.1 & 120.6 & 212.4 & 117.8 \\
\hline 5 & 30.7 & 129.6 & 209.2 & 130.6 \\
\hline 6 & 33.1 & 133.3 & 213.9 & 128.3 \\
\hline 7 & 36.5 & 133.8 & 210.4 & 133.3 \\
\hline 8 & 35.8 & 140.1 & 217.9 & 129.8 \\
\hline 9 & 36.5 & 130.6 & 209.9 & 130.7 \\
\hline 10 & 31.4 & 142.9 & 210.9 & 141.6 \\
\hline 11 & 31.9 & 141.2 & 215.1 & 134.3 \\
\hline 12 & 34.7 & 152.2 & 212.4 & 148.6 \\
\hline 13 & 34.9 & 143.3 & 210.9 & 142.0 \\
\hline 14 & 32.6 & 145.0 & 211.2 & 143.3 \\
\hline 15 & 30.8 & 154.5 & 212.0 & 151.5 \\
\hline 16 & 30.1 & 149.9 & 211.7 & 147.4 \\
\hline \multicolumn{5}{|c|}{ Visit No. 7} \\
\hline 1 & 40.9 & 122.2 & 209.3 & 123.1 \\
\hline 2 & 46.7 & 137.1 & 211.0 & 135.7 \\
\hline 3 & 45.1 & 138.7 & 213.9 & 133.5 \\
\hline 4 & 41.1 & 147.2 & 211.5 & 145.0 \\
\hline 5 & 56.8 & 147.3 & 209.8 & 147.6 \\
\hline 6 & 54.3 & 156.2 & 216.1 & 147.2 \\
\hline 7 & 54.5 & 156.8 & 213.2 & 151.9 \\
\hline 8 & 42.7 & 159.8 & 219.6 & 145.8 \\
\hline 9 & 48.1 & 152.0 & 213.7 & 146.6 \\
\hline 10 & 49.1 & 157.5 & 218.0 & 145.8 \\
\hline 11 & 42.0 & 157.3 & 216.3 & 148.0 \\
\hline 12 & 45.9 & 160.6 & 213.6 & 155.0 \\
\hline 13 & 48.6 & 171.6 & 219.6 & 156.6 \\
\hline 14 & 46.9 & 187.5 & 225.7 & 162.1 \\
\hline 15 & 44.5 & 201.5 & 234.4 & 162.0 \\
\hline 16 & 42.5 & 190.0 & 217.3 & 17.1 \\
\hline
\end{tabular}




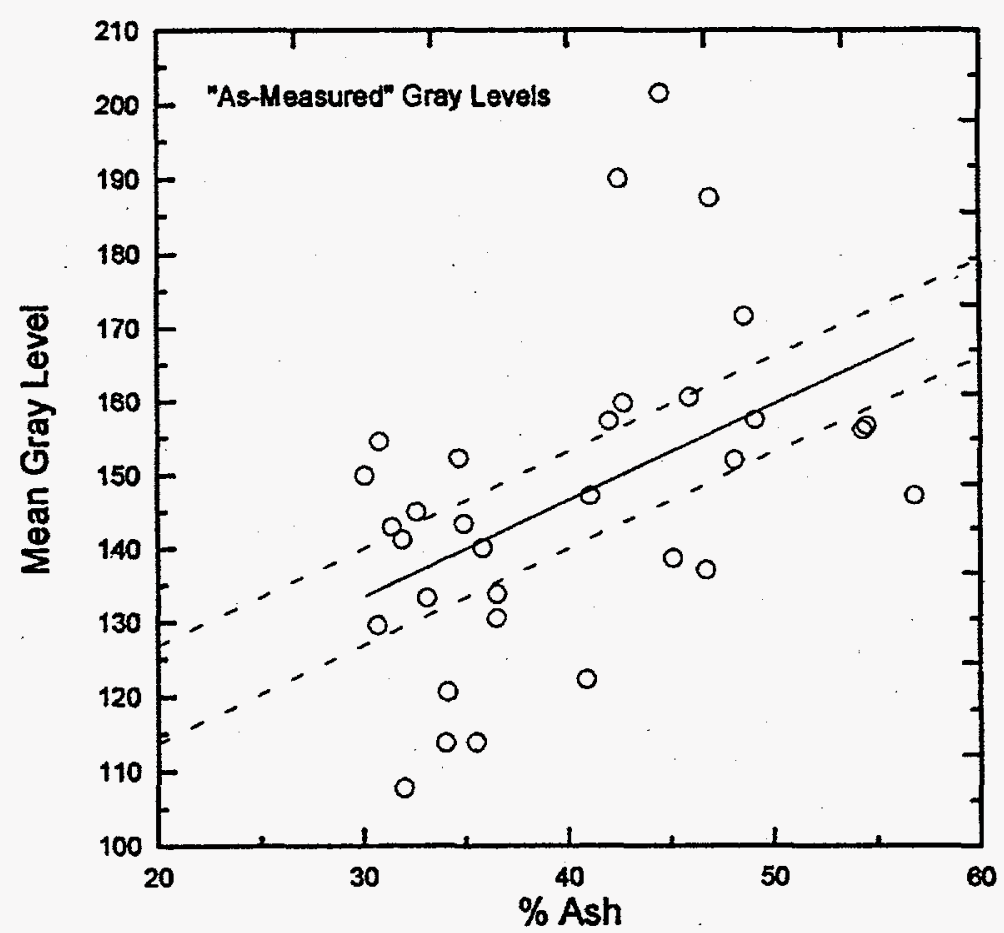

Figure 13. Video sensor calibration curve obtained from plant visits 6 and 7 showing the original data "as measured". The error bar indicates $\pm 5 \%$ ash.

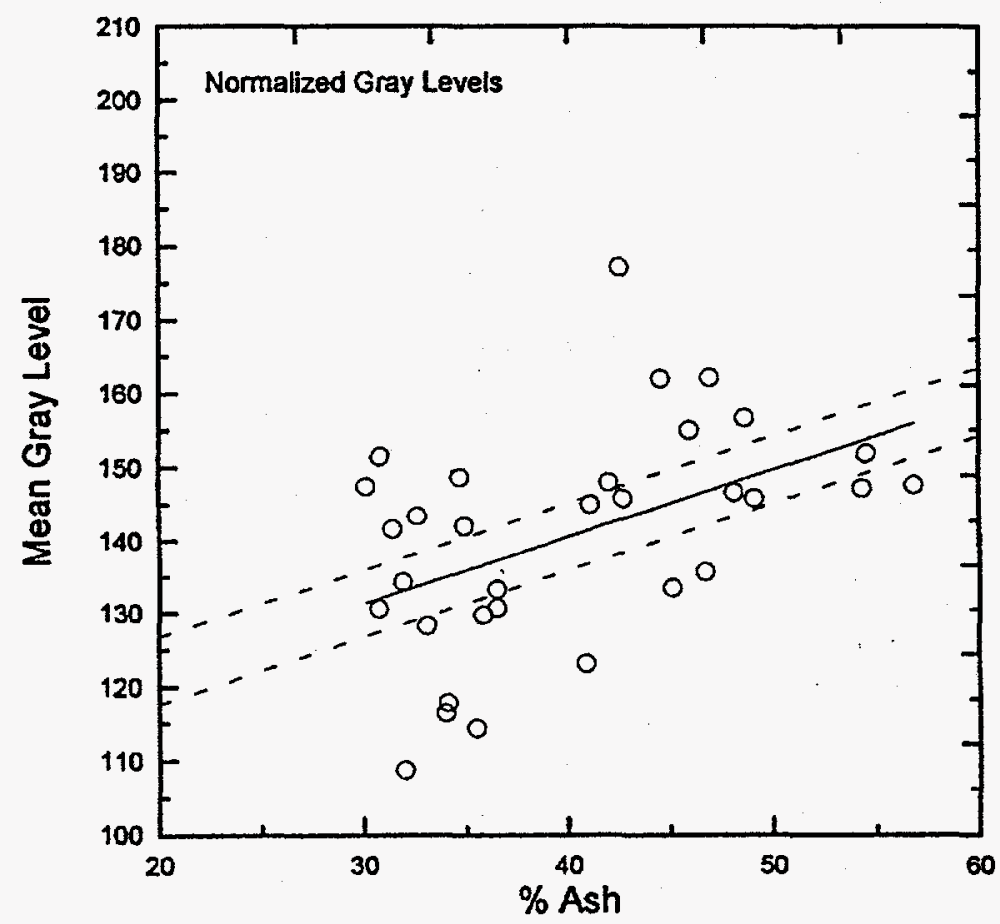


Figure 14. Video sensor calibration curve obtained from plant visits 6 and 7 showing mean gray levels normalized according to the percentage change in the standard. The error bar indicates $\pm 5 \%$ ash.

In summary, calibration data have been obtained for the video-based ash analyzer which show that over a range from $30-65 \%$ ash, the analyzer can achieve a resolution of approximately $0.8-1.0 \%$ ash per gray level increment. Unfortunately only $50-70 \%$ of the data points lie within $+5 \%$ ash of the calibration line. Thus, the accuracy of the sensor is poor. A gray level standard has been used to compensate for the effects of fluctuations in the incident light. After the gray level data are normalized for fluctuations in lighting, the data scatter appears to be reduced somewhat, but the normalization procedure does not seem to have a significant impact. It is theorized at this point that the scatter in the data is caused by the coarse size of the material being analyzed. In almost all cases, $50-65 \%$ of the tailings slurry appears to be +100 mesh material. It is doubtful that this material ever makes it to the surface of the slurry in the sampling tube to have an effect on the gray level of the slurry. Thus, changes in the ash content of the +100 mesh fraction would show up as scatter in the data, while the overall trend of increasing gray level with increasing ash content should be reflected in both the +100 and the 100 mesh fractions. It is expected that if the gray-level data were to be correlated to the ash content of the -100 mesh material, the scatter in the calibration curve would be significantly reduced.

At this point, it is the recommendation of VPI\&SU that preparations be made to lease a nuclear-based slurry ash analyzer to complete this project. At the same time, it is possible that the video-based analyzer may provide a useful means of measuring the tailings ash content in the -100 mesh fraction. Thus, VPI\&SU will continue to investigate this possibility. Such a measurement may provide additional useful information for a model-based control system.

Subtask 4.2 - Sensor Design, Procurement and Fabrication: As discussed under Subtask 4.1, the fluctuating power supply at the Maple Meadow plant site caused the light intensity on the video analyzer to vary. As a result, considerable scatter was encountered in the gray level data obtained at a given ash content. In order to compensate for the varying light intensity, a calibration standard was incorporated into the sample presentation tube. The calibration standard consisted of a PVC insert which was sealed from all outside illumination and placed 
within the field-of-view of the camera. As shown in Figure 15, this arrangement provides an image with the standard in one corner and the slurry in the rest of the field-of-view. The OPTIMAS software allows the standard to be separated from the slurry as a separate object so that the gray-level distributions of both objects can be measured and recorded. The gray-level information is then used, as described in Subtask 4.1, to provide normalized data.

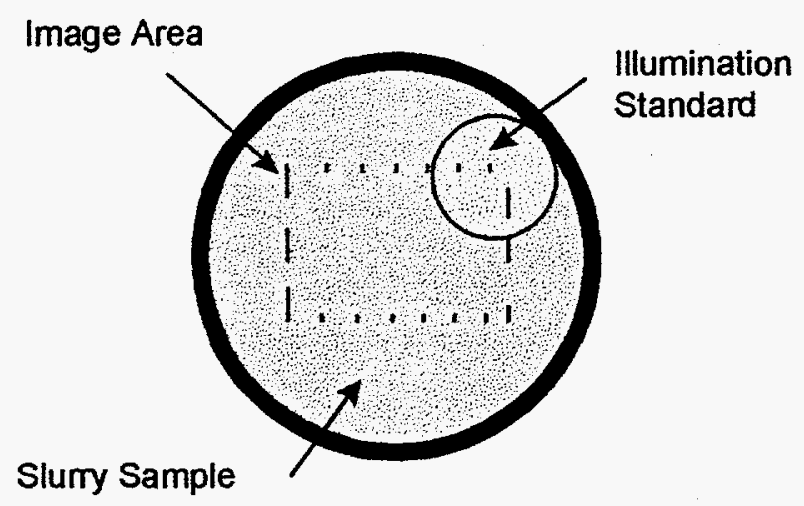

Figure 15. Focal plane of the sample presentation tube showing the calibration standard.

\section{Task 5 - Sample Analysis and Characterization}

Analyses for ash content, solids content and size distribution continue to be carried out as samples are collected under Tasks 2 and 4. 


\section{SUMMARY STATUS AND FUTURE WORK}

Major accomplishments during the past quarter are listed as follows:

1. The audit of the Maple Meadow flotation circuit was completed in conjunction with personnel from Control International. All samples were collected and preliminary data analysis has been performed.

2. Preliminary data analysis indicates that the sampling data during plants tests is suitable for model parameterization.

2. In order to improve the performance of the video-based ash analyzer, size-by-size analyses of the feed, concentrate and tailings from the Maple Meadow flotation circuit were conducted to characterize the mineral matter present in the slurry. In general, the following conclusions can be made:

- The tailings ash content generally ranges from $30-65 \%$. This ash appears to be relatively evenly distributed throughout all size classes. The amount of fine clay is minimal.

- All samples appear to be relatively coarse. In general, $50-70 \%$ of the tailings material is in the +100 mesh size range. Thus, the coarse material has the biggest influence on the ash content of the tailings. Since it is likely that this material is not visible to the video analyzer, the use of the video-based sensor in this particular application may be difficult.

- The clean coal yield is generally high ( $>85 \%$ ), but there appears to be room for improvement. Release analysis testing indicates that yield could be increased by $5-10$ percentage points while maintaining a concentrate ash content below $6 \%$. Such an improvement in the clean coal yield should increase the tailings ash content. This may improve the performance of the video-based analyzer.

3. Five site visits were conducted during the past quarter for the purpose of testing and calibrating the video sensor. The following summarizes the findings from these visits.

- Fluctuations in the plant power created a problem with the illumination system for the sensor. This problem was solved by incorporating a standard into the sample presentation tube. Several methods of normalizing the gray-level data using the standard were examined. An approach based on adjusting the mean gray level of the sample according to the percentage change in the standard appeared to be the most appropriate.

- Numerous samples were brought back to VPI\&SU for development of a sensor calibration curve. In general, the calibration appears to have a resolution of $0.8-1.0 \%$ ash per gray-level increment. Unfortunately, the scatter in the data is so severe that the accuracy of the sensor cannot be trusted. It appears that the scatter is caused by the coarse size of the material. 
At this time, it is the recommendation of VPI\&SU that the prime contractor consider the alternative of leasing another slurry ash analyzer. This could be the ash probe available from AMDEL. It does not appear that the video-based ash analyzer will be sufficiently accurate in this particular application due to the coarse particle size of the material in the slurry. At the same time, work should continue on the video-based ash analyzer to see if it can be used to monitor the ash content of the -100 mesh fraction of the tailings slurry. This additional information might be very useful in a model-based control system such as is being developed here.

In terms of the project status, the project appears to be approximately 4-5 months behind schedule due to delays in getting started and the reorganization at Control International. This project will be novated so that VPI\&SU will be the prime contractor and J. A. Herbst and Associates will be a subcontractor. Once this changes has been made, the project should be on track very quickly. 


\section{Appendix I}

Steady State Factorial Design Test Analysis 
Size-by-Size Analyses

\begin{tabular}{|c|c|c|c|c|c|c|}
\hline \multirow[b]{2}{*}{ Test } & \multirow[b]{2}{*}{ Stream } & \multirow[b]{2}{*}{ Size } & \multicolumn{2}{|c|}{1.50 Float } & \multicolumn{2}{|c|}{ 1.50 Sink } \\
\hline & & & Wt \% & Ash \% & $\mathrm{Wt} \%$ & Ash \% \\
\hline \multirow[t]{12}{*}{$\overline{\text { F1 }}$} & Feed & +28 & 91.67 & 3.33 & 8.33 & 60.03 \\
\hline & & $28 \times 48$ & 92.73 & 3.68 & 7.27 & 60.3 \\
\hline & & $48 \times 100$ & 91.57 & 4.2 & 8.43 & 59.82 \\
\hline & & -100 & 84.46 & 8.46 & 15.54 & 51.31 \\
\hline & Conc & +28 & 97.88 & 2.79 & 2.12 & 50.22 \\
\hline & & $28 \times 48$ & 98.16 & 2.94 & 1.84 & 50.68 \\
\hline & & $48 \times 100$ & 96.32 & 3.43 & 3.68 & 51.5 \\
\hline & & -100 & 92.94 & 5.63 & 7.06 & 36.79 \\
\hline & Tails & +28 & 41.32 & 7.1 & 58.68 & 50.71 \\
\hline & & $28 \times 48$ & 45.95 & 7.22 & 54.05 & 59.99 \\
\hline & & $48 \times 100$ & 36.36 & 7.75 & 63.64 & 63.03 \\
\hline & & -100 & 13.05 & 5.97 & 86.95 & 54.57 \\
\hline \multirow[t]{12}{*}{ F2 } & Feed & +28 & 85 & 5.02 & 15 & 71.8 \\
\hline & & $28 \times 48$ & 84.59 & 3.52 & 15.41 & 75.69 \\
\hline & & $48 \times 100$ & 79.42 & 3.46 & 20.58 & 76.36 \\
\hline & & -100 & 66.43 & 10.52 & 33.57 & 49.17 \\
\hline & Conc & +28 & 99.44 & 2.57 & 0.56 & 47.62 \\
\hline & & $28 \times 48$ & 97.42 & 3.43 & 2.58 & 50.22 \\
\hline & & $48 \times 100$ & 94.94 & 3.91 & 5.06 & 52.74 \\
\hline & & -100 & 91.56 & 6.35 & 8.44 & 38.26 \\
\hline & Tails & +28 & 32.95 & 8.65 & 67.05 & 56.17 \\
\hline & & $28 \times 48$ & 28.51 & 8.68 & 71.49 & 60.74 \\
\hline & & $48 \times 100$ & 21.37 & 7.92 & 78.63 & 64.11 \\
\hline & & -100 & 10.79 & 5.76 & 89.21 & 51.44 \\
\hline \multirow[t]{12}{*}{ F3 } & Feed & +28 & 93.75 & 4.07 & 6.25 & 49.33 \\
\hline & & $28 \times 48$ & 81.37 & 4.97 & 18.63 & 35.81 \\
\hline & & $48 \times 100$ & 92.76 & 4 & 7.24 & 38.91 \\
\hline & & -100 & 82.95 & 8.7 & 17.05 & 32.96 \\
\hline & Conc & +28 & 99.26 & 3.15 & 0.74 & 58.85 \\
\hline & & $28 \times 48$ & 99.17 & 2.67 & 0.83 & 41.19 \\
\hline & & $48 \times 100$ & 98.4 & 2.91 & 1.6 & 39.73 \\
\hline & & -100 & 94.85 & 4.96 & 5.15 & 31.45 \\
\hline & Tails & +28 & 43 & 7.25 & 57 & 59.61 \\
\hline & & $28 \times 48$ & 39.67 & 6.88 & 60.33 & 56.02 \\
\hline & & $48 \times 100$ & 37.23 & 6.45 & 62.77 & 56.35 \\
\hline & & -100 & 11.98 & 7.36 & 88.02 & 42.95 \\
\hline
\end{tabular}


Size-by-Size Analyses

\begin{tabular}{|c|c|c|c|c|c|c|}
\hline \multirow[b]{2}{*}{ Test } & \multirow[b]{2}{*}{ Stream } & \multirow[b]{2}{*}{ Size } & \multicolumn{2}{|c|}{1.50 Float } & \multicolumn{2}{|c|}{1.50 Sink } \\
\hline & & & $\mathrm{Wt} \%$ & Ash \% & Wt $\%$ & Ash \% \\
\hline \multirow[t]{12}{*}{ F4 } & Feed & +28 & 88.57 & 3.27 & 11.43 & 62.37 \\
\hline & & $28 \times 48$ & 90.85 & 5.14 & 9.15 & 58.83 \\
\hline & & $48 \times 100$ & 89.8 & 4.04 & 10.2 & 59.73 \\
\hline & & -100 & 87.36 & 11.22 & 12.64 & 62.16 \\
\hline & Conc & +28 & 98.9 & 3.99 & 1.1 & 48.23 \\
\hline & & $28 \times 48$ & 98.46 & 3.32 & 1.54 & 40.06 \\
\hline & & $48 \times 100$ & 97.2 & 3.22 & 2.8 & 43.85 \\
\hline & & -100 & 96.76 & 5.37 & 3.24 & 53.73 \\
\hline & Tails & +28 & 45 & 7.51 & 55 & 73.18 \\
\hline & & $28 \times 48$ & 26.51 & 7.96 & 73.49 & 59.97 \\
\hline & & $48 \times 100$ & 20.46 & 7.1 & 79.54 & 61.92 \\
\hline & & -100 & 1.8 & 6.68 & 98.2 & 47.94 \\
\hline \multirow[t]{12}{*}{ F5 } & Feed & +28 & 90.63 & 4.33 & 9.37 & 61.44 \\
\hline & & $28 \times 48$ & 89.51 & 4.83 & 10.49 & 67.47 \\
\hline & & $48 \times 100$ & 86.04 & 3.85 & 13.96 & 67.42 \\
\hline & & -100 & 62.22 & 7.91 & 37.78 & 41.14 \\
\hline & Conc & +28 & & & & \\
\hline & & $28 \times 48$ & & & & \\
\hline & & $48 \times 100$ & & & & \\
\hline & & -100 & & & & \\
\hline & Tails & +28 & & & & \\
\hline & & $28 \times 48$ & & & & \\
\hline & & $48 \times 100$ & & & & \\
\hline & & -100 & & & & \\
\hline \multirow[t]{12}{*}{ F6 } & Feed & +28 & 93.02 & 4.74 & 6.98 & 69.36 \\
\hline & & $28 \times 48$ & 89.95 & 3.98 & 10.05 & 67.46 \\
\hline & & $48 \times 100$ & 88.24 & 3.74 & 11.76 & 73.07 \\
\hline & & -100 & 81.48 & 8.72 & 18.52 & 55.26 \\
\hline & Conc & +28 & 99.42 & 3.27 & 0.58 & 43.91 \\
\hline & & $28 \times 48$ & 98.02 & 3.24 & 1.98 & 41.68 \\
\hline & & $48 \times 100$ & 96.16 & 3.19 & 3.84 & 48.33 \\
\hline & & -100 & 95.19 & 5.93 & 4.81 & 57.84 \\
\hline & Tails & +28 & 29.57 & 9.2 & 70.43 & 55.02 \\
\hline & & $28 \times 48$ & 19.39 & 9.08 & 80.61 & 55.73 \\
\hline & & $48 \times 100$ & 13.23 & 6.77 & 86.77 & 65.17 \\
\hline & & -100 & 6.84 & 3.72 & 93.16 & 49.3 \\
\hline
\end{tabular}


Size-by-Size Analysis

\begin{tabular}{|c|c|c|c|c|c|c|}
\hline \multirow{2}{*}{ Test } & \multirow[b]{2}{*}{ Stream } & \multirow[b]{2}{*}{ Size } & \multicolumn{2}{|c|}{ 1.50 Float } & \multicolumn{2}{|c|}{$1.50 \mathrm{Sink}$} \\
\hline & & & $\mathrm{Wt} \%$ & Ash \% & Wt \% & Ash \% \\
\hline \multirow{12}{*}{ F7 } & Feed & +28 & 84.5 & 4.11 & 15.5 & 68.34 \\
\hline & & $28 \times 48$ & 88.47 & 5.42 & 11.53 & 67.46 \\
\hline & & $48 \times 100$ & 85.23 & 3.59 & 14.77 & 66.33 \\
\hline & & -100 & 77.44 & 8.68 & 22.56 & 57.91 \\
\hline & Conc & +28 & 99.38 & 2.89 & 0.62 & 40.83 \\
\hline & & $28 \times 48$ & 99.01 & 3.04 & 0.99 & 38.86 \\
\hline & & $48 \times 100$ & 98.14 & 2.78 & 1.86 & 40.03 \\
\hline & & -100 & 97.84 & 5.12 & 2.16 & 37.21 \\
\hline & Tails & +28 & 32.31 & 7.2 & 67.69 & 51.72 \\
\hline & & $28 \times 48$ & 35.62 & 7.43 & 64.38 & 54.13 \\
\hline & & $48 \times 100$ & 31.01 & 7.41 & 68.99 & 57.71 \\
\hline & & -100 & 7.66 & 6.29 & 92.34 & 43.99 \\
\hline \multirow[t]{12}{*}{ F8 } & Feed & +28 & 85.19 & 4.02 & 14.81 & 65.07 \\
\hline & & $28 \times 48$ & 89.21 & 5.82 & 10.79 & 67.78 \\
\hline & & $48 \times 100$ & 88.51 & 4.66 & 11.49 & 60.88 \\
\hline & & -100 & 81.96 & 12.85 & 18.04 & 60.47 \\
\hline & Conc & +28 & 98.43 & 2.95 & 1.57 & 36.78 \\
\hline & & $28 \times 48$ & 96.91 & 3.07 & 3.09 & 34.98 \\
\hline & & $48 \times 100$ & 95.19 & 3.12 & 4.81 & 47.91 \\
\hline & & -100 & 96.12 & 5.69 & 3.88 & 56.24 \\
\hline & Tails & +28 & 27.45 & 8 & 72.55 & 58.41 \\
\hline & & $28 \times 48$ & 30.54 & 6.67 & 69.46 & 57.97 \\
\hline & & $48 \times 100$ & 31.29 & 5.85 & 68.71 & 59.98 \\
\hline & & -100 & 6.61 & 5.69 & 93.39 & 46.78 \\
\hline \multirow[t]{12}{*}{ F9 } & Feed & +28 & 84.96 & 4.07 & 15.04 & 70.62 \\
\hline & & $28 \times 48$ & 80.26 & 4.22 & 19.74 & 48.9 \\
\hline & & $48 \times 100$ & 76.72 & 4.21 & 23.28 & 54.08 \\
\hline & & -100 & 41.07 & 9.85 & 58.93 & 55.57 \\
\hline & Conc & +28 & 98.55 & 3.34 & 1.45 & 46.06 \\
\hline & & $28 \times 48$ & 98.58 & 2.81 & 1.42 & 40.2 \\
\hline & & $48 \times 100$ & 96.44 & 3.1 & 3.56 & 46.87 \\
\hline & & -100 & 96.29 & 5.65 & 3.71 & 49.79 \\
\hline & Tails & +28 & 18.84 & 7.89 & 81.16 & 46.8 \\
\hline & & $28 \times 48$ & 33.22 & 8.72 & 66.78 & 64.87 \\
\hline & & $48 \times 100$ & 26.02 & 9.07 & 73.98 & 66.92 \\
\hline & & -100 & 14.37 & 6.12 & 85.63 & 53.59 \\
\hline
\end{tabular}


Size-by-Size Analyses

\begin{tabular}{|ccc|cc|cc|}
\hline & & \multirow{2}{*}{ Size } & \multicolumn{2}{|c|}{1.50 Float } & \multicolumn{2}{c|}{1.50 Sink } \\
Test & Stream & & Wt $\%$ & Ash \% & Wt \% & Ash \% \\
\hline F10 & Feed & +28 & 92.45 & 4.39 & 7.55 & 63.11 \\
& & $28 \times 48$ & 91.23 & 3.79 & 8.77 & 67.73 \\
& & $48 \times 100$ & 88.45 & 3.24 & 11.55 & 68.63 \\
& -100 & 87.59 & 9.69 & 12.41 & 65.04 \\
& Conc & +28 & 99.51 & 2.92 & 0.49 & 39.75 \\
& $28 \times 48$ & 98.39 & 3.12 & 1.61 & 31.8 \\
& $48 \times 100$ & 96.93 & 3.04 & 3.07 & 36.21 \\
& -100 & 95.11 & 4.79 & 4.89 & 44.38 \\
& Tails & +28 & 31.41 & 7.64 & 68.59 & 53 \\
& $28 \times 48$ & 28.94 & 8.18 & 71.06 & 58.2 \\
& $48 \times 100$ & 18.56 & 7.1 & 81.44 & 62.16 \\
& -100 & 3.89 & 4.45 & 96.11 & 47.76 \\
\hline
\end{tabular}


Bulk Analyses

\begin{tabular}{|c|c|c|c|c|}
\hline Test & Stream & $\%$ Solids & Ash & Sulfur \\
\hline \multirow[t]{3}{*}{ F1 } & Feed & 6.11 & 11.23 & 0.98 \\
\hline & Conc & 16.52 & 5.89 & 0.86 \\
\hline & Tails & 3.24 & 40.59 & 1.64 \\
\hline \multirow[t]{3}{*}{$\mathrm{F} 2$} & Feed & 9.92 & 19.01 & 1.47 \\
\hline & Conc & 17.6 & 6.32 & 0.86 \\
\hline & Tails & 2.94 & 47.46 & 1.7 \\
\hline \multirow[t]{3}{*}{ F3 } & Feed & 5.11 & 10.08 & 1.09 \\
\hline & Conc & 14.86 & 6.32 & 0.86 \\
\hline & Tails & 3.51 & 39.18 & 1.58 \\
\hline \multirow[t]{3}{*}{ F4 } & Feed & 6.21 & 13.5 & 1.06 \\
\hline & Conc & 16.7 & 5.15 & 0.84 \\
\hline & Tails & 2.49 & 45.96 & 1.69 \\
\hline \multirow[t]{3}{*}{ F5 } & Feed & 6.69 & 14.56 & 1.06 \\
\hline & Conc & 15.76 & 5.17 & 0.82 \\
\hline & Tails & 3.33 & 41.17 & 1.71 \\
\hline \multirow[t]{3}{*}{ F6 } & Feed & 7.19 & 13.56 & 1.11 \\
\hline & Conc & 14.34 & 5.98 & 0.9 \\
\hline & Tails & 2.17 & 49.36 & 1.93 \\
\hline \multirow[t]{3}{*}{ F7 } & Feed & 6.38 & 14.94 & 1.12 \\
\hline & Conc & 15.58 & 4.82 & 0.78 \\
\hline & Tails & 3.29 & 40.38 & 1.46 \\
\hline \multirow[t]{3}{*}{ F8 } & Feed & 6.15 & 17.18 & 1.24 \\
\hline & Conc & 16.69 & 6.09 & 0.81 \\
\hline & Tails & 3.5 & 41.7 & 1.23 \\
\hline \multirow[t]{3}{*}{ F9 } & Feed & 11.48 & 22.4 & 1.68 \\
\hline & Conc & 20.31 & 4.82 & 0.75 \\
\hline & Tails & 2.77 & 45.66 & 1.68 \\
\hline \multirow[t]{3}{*}{ F10 } & Feed & 7.35 & 11.68 & 1.07 \\
\hline & Conc & 16.71 & 4.55 & 0.87 \\
\hline & Tails & 2.94 & 43.77 & 1.96 \\
\hline
\end{tabular}


Appendix II

Residence Time Distribution Test

Lithium Analysis 


\begin{tabular}{cc}
\hline Time & $\begin{array}{c}\text { Lithium } \\
\mathrm{mg} / 1\end{array}$ \\
\hline 0 & 0.194 \\
0 & 0.195 \\
30 & 0.201 \\
60 & 1.857 \\
90 & 5.667 \\
120 & 9.415 \\
150 & 11.15 \\
180 & 12.07 \\
210 & 11.6 \\
240 & 11.15 \\
270 & 10.93 \\
300 & 9.54 \\
360 & 7.65 \\
420 & 6.54 \\
480 & 5.14 \\
540 & 4.12 \\
600 & 3.267 \\
660 & 2.588 \\
720 & 2.009 \\
\hline
\end{tabular}


Appendix III

Disturbance Characterization Test

Batch Lab Float Analyses 


\begin{tabular}{|c|c|c|c|ccc|ccc|}
\hline \multirow{2}{*}{ Sample } & \multirow{2}{*}{ Time } & \multicolumn{2}{|c|}{ Feed } & \multicolumn{3}{c|}{ Concentrate } & \multicolumn{3}{c|}{ Tails } \\
\cline { 3 - 9 } & Ash & Sulfur & Wt \% & Ash & Sulfur & Wt \% & Ash & Sulfur \\
\hline 1 & 0 & 16.30 & 1.65 & 62.37 & 5.22 & 0.93 & 37.63 & 34.67 & 2.85 \\
2 & 10 & 11.89 & 1.16 & 70.00 & 4.71 & 0.86 & 30.00 & 28.64 & 1.85 \\
3 & 20 & 13.76 & 1.08 & 69.19 & 5.10 & 0.85 & 30.81 & 33.21 & 1.59 \\
4 & 30 & 13.33 & 1.13 & 68.07 & 5.14 & 0.87 & 31.93 & 30.78 & 1.68 \\
5 & 40 & 11.96 & 1.11 & 68.66 & 4.68 & 0.89 & 31.34 & 27.92 & 1.6 \\
6 & 50 & 12.22 & 0.91 & 70.13 & 5.13 & 0.89 & 29.87 & 28.88 & 0.95 \\
7 & 60 & 11.31 & 1.21 & 73.94 & 5.23 & 0.95 & 26.06 & 28.57 & 1.95 \\
8 & 80 & 11.99 & 1.17 & 73.64 & 4.26 & 0.82 & 26.36 & 33.60 & 2.16 \\
9 & 100 & 11.57 & 1.03 & 65.98 & 4.57 & 0.79 & 34.02 & 25.15 & 1.5 \\
10 & 120 & & 0.53 & 61.06 & 4.43 & 0.86 & 38.94 & & \\
11 & 160 & 11.76 & 1.07 & 70.49 & 4.54 & 0.89 & 29.51 & 28.99 & 1.5 \\
12 & 200 & 10.98 & 1.03 & 68.09 & 4.16 & 0.85 & 31.91 & 25.54 & 1.41 \\
13 & 240 & 12.33 & 0.93 & 71.80 & 4.83 & 0.80 & 28.20 & 31.44 & 1.27 \\
14 & 320 & 12.45 & 0.97 & 65.25 & 4.78 & 0.79 & 34.75 & 26.85 & 1.3 \\
15 & 400 & 12.36 & 0.79 & 66.48 & 4.17 & 0.70 & 33.52 & 28.60 & 0.96 \\
16 & 480 & 12.47 & 1.17 & 67.61 & 4.53 & 1.08 & 32.39 & 29.04 & 1.35 \\
17 & 640 & 12.28 & 0.87 & 68.56 & 4.43 & 0.71 & 31.44 & 29.39 & 1.22 \\
18 & 800 & 10.14 & 0.93 & 72.15 & 3.90 & 0.79 & 27.85 & 26.30 & 1.31 \\
19 & 960 & 11.17 & 0.97 & 59.50 & 4.35 & 0.80 & 40.50 & 21.19 & 1.21 \\
\hline
\end{tabular}

